San Jose State University

SJSU ScholarWorks

Dissertations

Master's Theses and Graduate Research

Spring 2018

\title{
A Feminist Critical Discourse Analysis of the National Board for Professional Teaching Standards
}

Melissa Urbain

San Jose State University

Follow this and additional works at: https://scholarworks.sjsu.edu/etd_dissertations

\section{Recommended Citation}

Urbain, Melissa, "A Feminist Critical Discourse Analysis of the National Board for Professional Teaching Standards" (2018). Dissertations. 22.

DOI: https://doi.org/10.31979/etd.c2p2-2wsx

https://scholarworks.sjsu.edu/etd_dissertations/22

This Dissertation is brought to you for free and open access by the Master's Theses and Graduate Research at SJSU ScholarWorks. It has been accepted for inclusion in Dissertations by an authorized administrator of SJSU ScholarWorks. For more information, please contact scholarworks@sjsu.edu. 


\title{
A FEMINIST CRITICAL DISCOURSE ANALYSIS OF THE NATIONAL BOARD FOR PROFESSIONAL TEACHING STANDARDS
}

\author{
A Dissertation \\ Presented to \\ The Faculty of the Educational Doctoral Program in Educational Leadership \\ San José State University \\ In Partial Fulfillment \\ of the Requirements for the Degree \\ Doctor of Education
}

by

Melissa Urbain

May 2018 
(C) 2018

Melissa Urbain

\section{ALL RIGHTS RESERVED}


The Designated Dissertation Committee Approves the Dissertation Titled

A FEMINIST CRITICAL DISCOURSE ANALYSIS OF THE NATIONAL BOARD FOR PROFESSIONAL TEACHING STANDARDS

\author{
by \\ Melissa Urbain \\ APPROVED FOR THE EDUCATIONAL DOCTORAL PROGRAM IN \\ EDUCATIONAL LEADERSHIP
}

SAN JOSÉ STATE UNIVERSITY

May 2018

Kathleen McConnell, Ph.D.

Department of Communication Studies

Tom Moriarty, Ph.D.

Department of English and

Comparative Literature

Colette Rabin, Ph.D.

Department of Teacher Education

Jan Chock, Ph.D.

California Public School Teacher 


\begin{abstract}
A FEMINIST CRITICAL DISCOURSE ANALYSIS OF THE NATIONAL BOARD FOR PROFESSIONAL TEACHING STANDARDS

by Melissa Urbain
\end{abstract}

This research is a feminist discourse analysis of the National Board for Professional Teaching Standards Five Core Propositions. The goal of this project is to shift the focus of educational discourse away from teachers' gender and look towards their teachers' teaching abilities as compared to the professional standards laid out in the NBPTS. It demonstrates that the national expectations placed on teachers are feminist and addresses and discredits current patriarchal discourse and policies in the field of education. This is accomplished through a close reading of the Five Core Propositions, drawing connections between the expectations in the document and the feminist values of care, diversity, and collaboration. The results uncover that the National Boards for Professional Teaching Standards espouse feminist values while discrediting patriarchal values. Because of this, the educational community must push policy makers and pundits to change their patriarchal expectations of teachers to align with the feminist values of the national standards. 


\section{ACKNOWLEDGMENTS}

This dissertation is a result of the efforts of many individuals. First, I send my deepest love and gratitude to Paul Nyhof. Your partnership throughout this academic journey was invaluable to its success. Your intellectual and emotional support carried us through many challenges and burdens that come along with and endeavors such as this.

Second, great appreciation is due to Dr. Kathleen McConnell, whose time, efforts, and dedication to this project was a tremendous help in seeing its completion. Her patient guidance over the course of this study made this process broadened my understanding of both education and the world. I would also like to thank Dr. Jan Chock, Dr. Thomas Moriarty, and Dr. Colette Rabin for their work and advice through this project.

My classmates have been the most powerful teachers throughout this experience. Arcia Dorasti, education needs more linebackers like you to tackle the injustices in our system. You've pushed us all to relentlessly question the status quo and refuse to operate in fear.

Lastly, I am forever indebted to my parents and brother for their tireless contributions to my education. My father for always reminding me that education is the one thing they can't take away from you. My mother for enduring the endless days of tutoring, homework help, and summer school. And my brother for always believing in my ability to accomplish more. 


\section{TABLE OF CONTENTS}

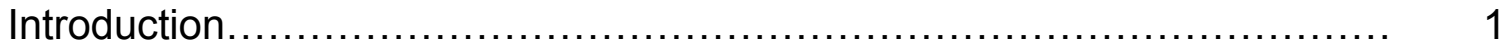

Discussions in Education: Remasculinization of Teaching ................ 2

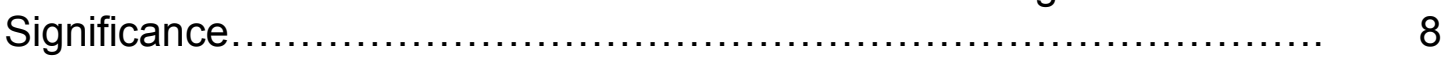

Moving Beyond Gender......................................... 9

Literature Review................................................... 13

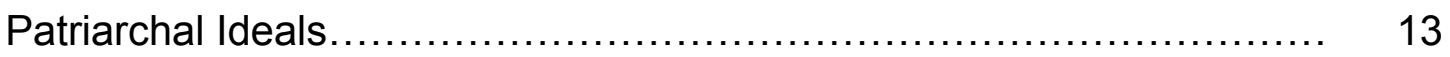

A Brief History of Feminist Traditions $\ldots \ldots \ldots \ldots \ldots \ldots \ldots \ldots \ldots \ldots \ldots \ldots \ldots, \quad 14$

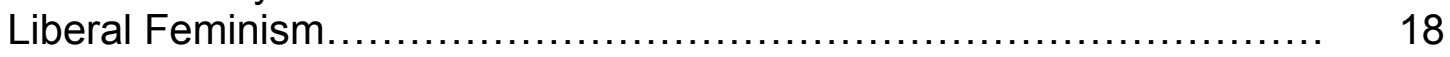

Cultural Feminism........................................................ 20

Feminist Values/Orientation............................................. 21

Hypermasculinity and Patriarchy..................................... 23

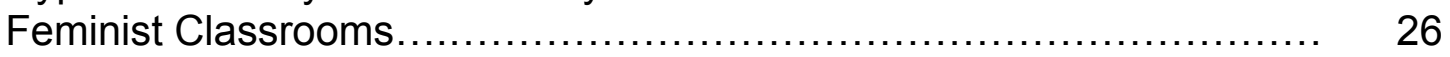

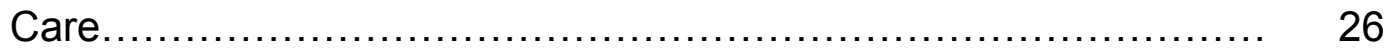

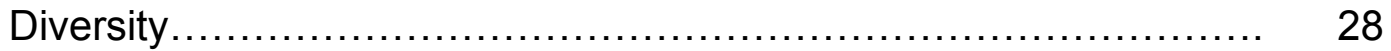

Collaboration.......................................................... 30

An Overview of the National Board for Professional Teaching Standards 33

The certification process .......................................... 34

National boards background .................................... 35

Other significant teaching standards $\ldots \ldots \ldots \ldots \ldots \ldots \ldots \ldots \ldots \ldots \ldots, \quad 38$

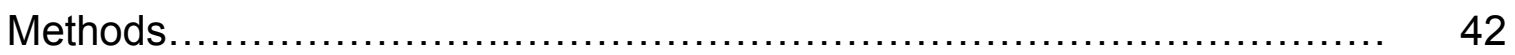

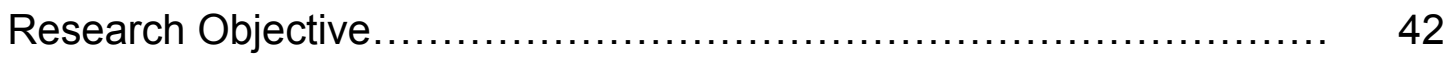

Feminist Discourse Analysis............................................ 44

Research Process................................................... 46

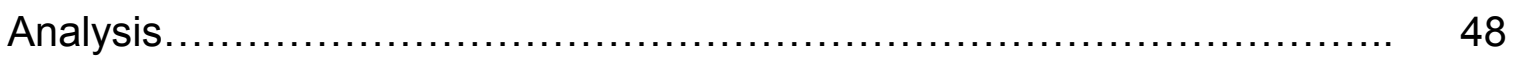

The Format of "What Teachers should Know and be Able to Do"........ 48

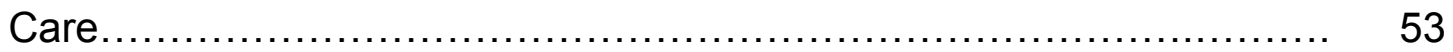

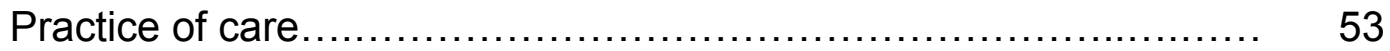

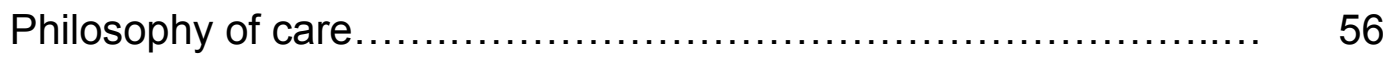

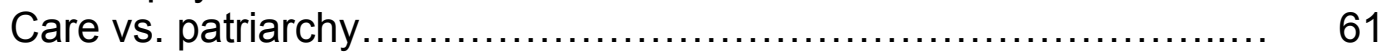

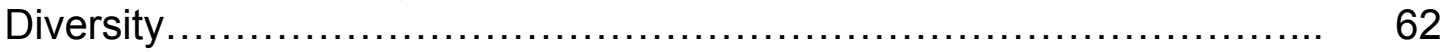

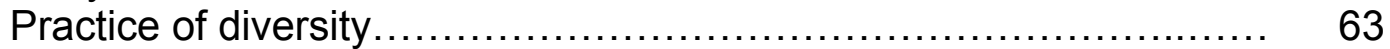

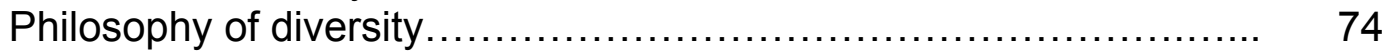

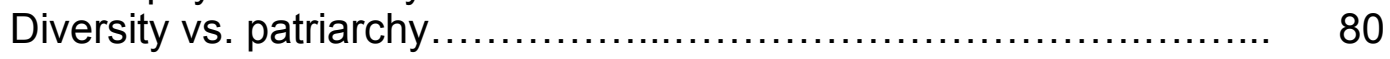

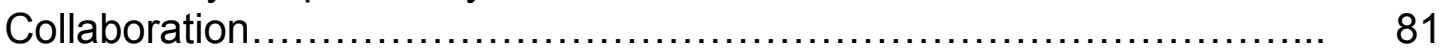

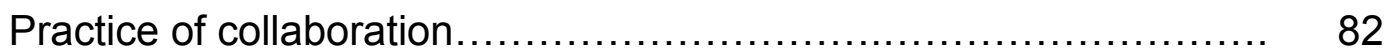

Philosophy of collaboration............................................. 92

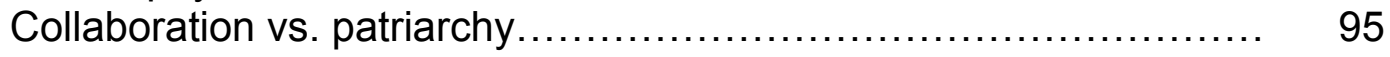

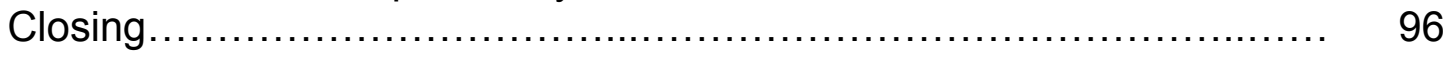




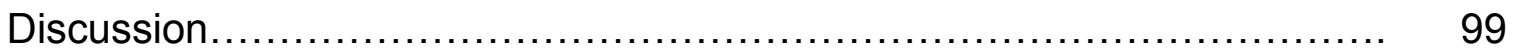

Teachers Carrying Guns ........................................... 100

National Discipline Policies.......................................... 101

Zero-Tolerance Policy ................................................... 102

Standardized Testing ................................................. 103

Teacher Evaluation and Merit Pay ................................... 104

Teach for America ....................................................... 106

Tracking ........................................................... 107

English Only - English Learner Programs that Claim Superiority to

Bilingual Programs .................................................... 108

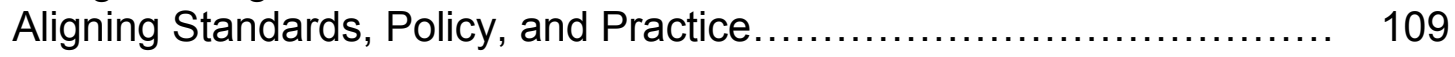

Areas of Further Study ............................................... 110

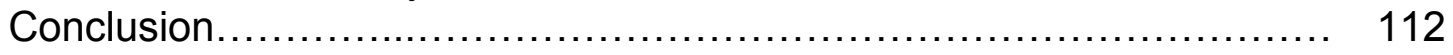

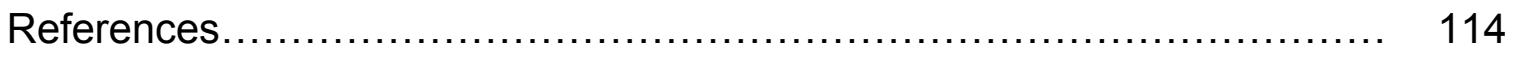




\section{CHAPTER 1 Introduction}

This dissertation offers a feminist discourse analysis of the National Board for Professional Teaching Standards (NBPTS) booklet "What Teachers Should Know and be Able to Do." The booklet articulates the Five Core Propositions (FCP), which are commonly known as the National Board Teaching Standards. The purpose of this research is to demonstrate how and where the FCP intersects with principles of feminist pedagogy. I do not claim that the authors of the FCP deliberately intended to incorporate feminist pedagogy into the text when writing the propositions. Instead, I demonstrate the NBPTS relevance and applicability of feminist philosophy by showing the parallels between the FCP and feminist pedagogical practices.

Feminist ethics and pedagogy encompass a variety of strategies rooted in the beliefs and values of feminist movements. While feminist pedagogical practices hold many values, this research exclusively focuses on three core feminist values shared by different feminist movements: care, diversity, and collaboration. Understanding the way feminist pedagogy defines these terms is essential to understanding how these values connect to the NBPTS. Caring is defined as having a fondness for the world and the people in it, while also developing a commitment to morally act on the behalf of others (Regan \& Brooks, 1995).

Diversity is defined as differences based on social categories like gender, race, sexuality, class, and others (Adams, 2013). Furthermore, an appreciation for

diversity is revealed in non-standardized forms of teaching practices and the 
implementation of teaching practices that illustrate the benefits of human difference (Griffith, 2006). Finally, collaboration is defined as the ability to work with a group, offering support to each other, and creating a synergistic environment for everyone (Regan \& Brooks, 1995). It is important to note that these definitions do not limit these values to one gender or another. Throughout this project, the term "feminism" is used as a construct of values any gender can practice, and is not used as a narrow term to define only women. Framing the discourse in terms of values rather than gender is critical in redirecting teacher training and teacher evaluation away from the question of who should teach and to focus instead on how we teach. To encourage this intervention, this study draws on feminism in two ways: First, it draws on feminist studies to challenge the idea that women and men have naturally different teaching styles. Secondly, it draws on feminist traditions that encourage care, diversity, and collaboration. This study aims to demonstrate that feminist values are not anchored to being a woman; therefore anyone can actualize these values in their pedagogical practices.

\section{Discussions in Education: "Remasculinization" of Teaching}

The need for this research has surfaced because there has been a public attack on females holding the majority of teaching positions in the profession. For well over 100 years, women have dominated the teaching profession in America and hold roughly $75 \%$ of the majority of teaching positions (Clifford, 1989; Rich, 2014). Even though women have long 
outnumbered their male counterparts in the teaching profession, public discourse has often asserted that male teachers are simply better than female teachers. When conducting a Google search of the term "male teachers," suggested phrases like, "benefits of male teachers" or "male vs. female teachers" appear on the drop down menu. Google's prediction that searchers would be interested in placing values judgments on male teachers demonstrate how ubiquitous this conversation about teachers' gender has become.

Along with this criticism, pundits often call for more male teachers in the profession. Some call for more male teachers because they believe students should have diverse teacher role models. Others think it is important that students have male teachers so that student can see males in caring nurturing roles like teachers. These perspectives may have merit and are worth further exploration, however this project does not address those parties' assertions. Furthermore, I caution any group who seeks to claim one group of teachers as being wholly "better" than another. Projects of these sorts, while possibly wellintended, often lead to the reinforcement of stereotypes and prejudice in society.

This research does address critics who believe male teachers are superior educators in the classroom due to the misguided belief that struggling male students need more authoritarian male teachers as role models. These critics call for a "re-masculinization" of schools and criticize female teachers, claiming that they prefer and favor female students. Some also assert male teachers 
enforce harsher discipline policies so that male students can behave properly (Biddulph, 1998; Mills, Martino, \& Lingard, 2004; Hoff-Sommers, 2000).

When looking at blogs, opinion sections, and discussion forums, men are ubiquitously favored over female teachers for the many attributes that are considered desirable and masculine. An article titled Discipline Fears as Female Teachers Outnumber Male Peers by 12 to 1 (2006) states that the decline in male teachers is, "fuelling fears of rising misbehavior among disaffected teenage boys whose lives lack male authority figures." This sentiment enforces negative stereotypes for both genders by suggesting that male students are unruly and that female teachers are unable to address unexpected behaviors that arise in a classroom setting. Furthermore, it depicts male teachers as disciplinarians and authority figures, which are both qualities valued in patriarchal systems. This stereotype of male teachers being disciplinarians has some basis in reality as evidenced by research regarding student discipline referrals. The University of Nebraska found that male teachers refer disciplinary action for students sixteen percent more than female teachers (Panko-Stilmock, 1996). These examples demonstrate the expectation for men to take punitive courses of action to address students' behavior.

Sexist and counterproductive assertions about the qualities of male and female teachers permeate educational discourse. Despite coming from people outside the teaching profession, these assertions have proven influential in causing misconceptions that lead to unsound hiring, teaching, and evaluation 
practices in the field (Skelton, 2003). When these assertions go unchecked, teachers find themselves pressured to use pedagogical approaches, which in some cases directly contradict professional literature on good teaching practices. Forcing dominance on a student by sending them out of the classroom for minor offences, rather than encouraging curiosity, can stifle and block the learning process causing greater problems in the classroom. It is important to challenge what we believe to be "common knowledge" about teaching practices and expose any detrimental ideals that these assumptions may carry.

Some claim that male students struggle with school because they do not have enough male teachers as role models (Skelton, 2003). Furthermore, critics claim females teachers prefer and favor girl students (Biddulph, 1998; Hoff-Sommers, 2000). Yet, there is an absence of solid evidence to support this claim. When discussing teacher gender, Skelton (2003) uncovers, "The majority of students appeared to hold an optimistic view of primary teaching as offering equal opportunities and primary schooling as a 'gender free' zone" (p. 206). This reveals that while adults may make assertions about female teachers favoring one gender over another, school children do not pay much notice to the gender of their teacher and therefore, it has little impact in their schooling.

Scholars continue to question the assertion that it is better to have male teachers for the sake of having an adult male gender in a boy's life. This claim serves to push hegemonically masculine ideals in schools (Apple, 2001; Martino \& Berrill, 2003). While mainstream popular media continues to claim that male 
teachers make more desirable role models for male students, scholars have argued that this is just an excuse to push the agenda of masculine ideals into classrooms because our children may be "at risk" of overexposure to feminized values in the context of school (Lingard, 2003; Mills, 2004; Mills, Martino \& Lingard, 2004). This research continues to question these assertions and builds on past research that refutes common stereotypes about gender and the teaching profession.

Instead of placing so much concern on the gender of a teacher, the focal point for improving the profession should be targeted at the philosophies and practices of our teachers. This requires the conversation to revolve around what teacher know and do in their classrooms. "Students continually reiterate that it is not so much the gender of the teacher but rather the quality of the pedagogy and the teacher-student relationship that matters most in their learning" (Martino \& Kehler, 2006, p. 125). This means that before schools push to recruit more male teachers for the sake of having men in the classroom, they must ask: what role can these men play in helping our students develop into healthy, empathetic, kind, caring, and curious learners who build these relationships with others?

The social investment in masculinity seems to underwrite the call for more male teachers, and is not rooted in a concern with student achievement. (Lingard, 2003; Mills, 2004; Mills, Martino, \& Lingard, 2004). The call for male teachers brings hyper-focused counterproductive attention to gender in the teaching profession. Decades of research support the case that there is little to 
no correlation between the gender of teachers and the success of their students. Bank, Biddle, \& Good (1980) assert, various studies have "found minimal differences in the effects of male and female teachers on behaviors and achievement of boys and girls" (121) (Asher \& Gottman, 1973; Brophy \& Laosa, 1971; Gross, 1976; Lahadrene \& Cohen, 1972). Drudy (2008) also reveals, "Most empirical studies and reviews indicate that sex of teachers has little, if any, effect on the achievement of pupils" (313) (Carrington, Francis, Hutchings, Skelton, Read \& Hall, 2007; Drudy, Martin, Woods, O’Flynn, 2005; Sabbe \& Aelterman, 2007). Despite knowing this for years, these assumptions about gender create a societal panic that students are "at-risk" of being under exposed to male role models, thus sending the message that good teaching has more to do with a teacher's gender identity than it has to do with mastery of specific professional skills.

The myth about a teachers' gender impacting student performance is perpetuated because many studies reveal that male and female students typically perform better in certain subject areas. For example, girls in the United States usually perform higher in reading while boys typically excel in math. There are many hypotheses behind why this may be the case; students' maturation, developmental stage, teacher bias, and teaching styles can all play a role in student achievement. However, when researchers consider these isolated factors with teacher gender in mind, they finds no definitive evidence that demonstrates the sole result of students' success is based on the teacher's 
gender. The data is weak and often tells a contradictory story, resulting in minimal differences in the effects on student achievement due to teacher gender (Bank, Biddle, \& Good, 1980). This further supports the need to continue researching effective pedagogical approaches to maximize student success.

\section{Significance}

In recent years, feminist pedagogy has been blamed for working class boys' poor performance in school. Working class boys have always performed lower on reading and literacy tests than other groups. However, it was not viewed as a crisis until feminism was blamed for the problem and portrayed as a threat to greater societal patriarchal structures (Mills \& Lingard, 1997). Digging deeper into the question of why boys perform worse in school it becomes clearer that it is patriarchal structures that limit and oppress these students. From a young age boys are told that they need to fit into a masculine paradigm (Newsom, 2015). If they want to be viewed as masculine, they have limited choices and outlets in which to explore. Due to patriarchal structures, they experience harassment if they pursue activities that are viewed as feminine. These limitations block them from many fulfilling opportunities (Newsom, 2015).

This campaign against feminist pedagogy is a significant problem because the overwhelming research on effective education rejects patriarchal pedagogical practices that seek to exercise control over groups of people based on stereotypes, such as beliefs about what boys should like. These problems do not occur when all students are exposed to feminist paradigms. For example, 
research shows that male students perform better in general when they are able to pursue a multitude of interests including those that have been traditionally viewed as feminine (Mills \& Lingard, 1997).

\section{Moving Beyond Gender}

The National Board for Professional Teaching Standards (NBPTS) is considered the national gold standard for teaching practices in the United States. The Five Core Propositions (FCP) are considered the five traits of effective, accomplished teachers throughout the country. Teachers across the nation can participate in the program and not only reflect on and improve their teaching practices, but also find financial reward and universal acceptance from most states' educational systems (Irvine, Belson, \& Husted, 2015). The NBPTS occupies a place of incredible significance for the teaching profession because of its public prestige and the fact that the National Board Teaching Certification can be obtained by any teacher with a bachelor's degree and at least three years of teaching experience. This leaves the opportunity to participate in the program open to the vast majority of teachers in the profession.

It should be noted that teachers can pursue other avenues of professional advancement such as professional development workshops, peer-to-peer coaching, and higher degrees of education such as Master's and Doctorate degrees. While these all offer tremendous support and opportunities for professional advancement, they are each unique, as they hold different focuses, emphasis, and opportunities for those teachers who choose to participate. In 
contrast, the NBPTS is the most standardized and widely accepted teacher development program in the country. Schools and communities universally hold up the FCP as effective pedagogical approaches for classroom teachers.

Because the NBPTS hold such great authority within the teaching profession, they have the power to shape, direct, and change national discourse regarding the teaching profession. Notably, the standards do not correlate with the gender of any teacher but only with the quality of their teaching practice. Since gender is not the focus of the FCP referencing them as the gold standard for the profession helps move conversations away from teachers' gender. The tendency to compare male and female teachers reinforces stereotypes and prejudice about both sexes. In place of gender stereotypes, the FCP encapsulates the expectations of the best of teaching philosophies and their expression through pedagogical practice. This allows for a shift of focus in discussion, moving away from gender stereotypes and toward philosophies and practices that can be effective for any teacher working in any school.

A close reading of the NBPTS shows that the document makes no connection between the gender identity of a teacher and a person's teaching ability nor does it espouse patriarchal values. On the contrary, the philosophy and practices advocated by FCP reflect three specific feminist values-care, diversity, and collaboration--which are not exclusive to one gender. My objective in showing a correspondence between FCP and feminist literature is to question whether a person's gender identity is relevant at all to their abilities as a teacher. 
The common misconceptions for why schools need more male teachers are the problem, not the question of whether men should be teachers. This project does not argue that male teachers are ineffective or unneeded in classrooms across the country. Regardless of one's gender, schools need quality teachers who use effective pedagogical strategies that do not encourage methods that endorse domination, oppression, or exploitation. Instead, this research seeks to refute the assumption that patriarchal pedagogical practices are valuable to students and schools. It will further advance the understanding of feminist pedagogical practices while also bringing a deeper understanding of the teaching qualities that are considered favorable and therefore mirror the current national standard for excellent teaching.

This research will aid in moving away from perspectives rooted in gender stereotypes by placing more worth on teachers' quality of work. Eliminating gender inequities and stereotypes is critical to ensuring that students receive the highest quality of instruction in their classrooms. This research will also reveal the tremendous inconsistency teachers experience in expectations. Educational policies often contradict the expectations of the NBPTS. This forces teachers to choose between following the rules or using national best practices. It is imperative to question any discourse about teachers' gender because it serves in maintaining patriarchal attitudes that favor the status quo. Pedagogical research must continue to question stereotypes and move the focus of educational discourse away from teachers' gender. The roles, practices, behaviors, and 
choices of teachers have far more impact on students' classroom performance than their gender identity. This is because students' perceptions about their teachers are shaped by the teaching practices, not their gender. The outcomes from these teaching practices, as best defined by the NBPTS, are what should be used to determine the quality of all teachers. 


\section{CHAPTER 2 Literature Review}

\section{Patriarchal Ideals}

In most situations the word patriarchy is synonymous with sexism and literally means "male rule over females" (Rothman, 1994). However, for this research the traditional understanding of the word will be modified and defined as a system of structures and practices that are used to dominate, oppress, and exploit others (Walby, 1990). This definition includes, but does not limit itself, to only oppressing females. The system is different from men simply hating women. It is larger and acts independently of beliefs and individual actions. For example, a woman cannot blame her male colleague for getting paid more than her. There is a bigger system involving groups perceptions, expectations, practices, and policies in place perpetuating this inequity.

Throughout this project, the term feminism will be used not as a term to define women, but as a construct of values, which any gender can practice. Framing the discourse in terms of values is critical in redirecting the conversation away from gender identity and focusing instead on effective teachers and teaching practice. Feminism and feminist approaches are a series of actions that reveal one's beliefs and assumptions about the world. Because feminism is not tied to being a woman, anyone can actualize feminist values in their pedagogical practices.

In the next section, I identify the feminist traditions that inform this study and how they differ from other feminist traditions. Some strands of feminism are 
concerned primarily with achieving equality between the sexes. This thinking can align with arguments in favor of achieving gender balance in teaching by hiring more male teachers. Other feminist traditions argue that gender is a social construct imposed on bodies and is not innate. This thinking questions any attempt to assign certain traits to certain bodies. In place of patriarchal thinking, it promotes feminist values that could be enacted by anybody. A commitment to care, diversity, and collaboration are central to those values.

\section{A Brief History of Feminist Traditions}

Some compare the American feminist movement to ocean waves. Approaching America's shores with a surge of energy, pushing and challenging accepted norms to move forward while also sweeping traditional notions of society away in order to bring up new ideas that change our understanding of each other. And like a wave, the movement disappears back into the ocean with an unsettling calm, yet we know that another is soon to arise with a stronger rush demanding progress and challenging us to thrust onwards into the future.

Historically, the first American feminist wave is considered to have begun in the 1840s (Hewitt, 2012). The Women's Suffrage Movement (Barnes \& Burns, 2003), began with the Seneca Falls Women's Rights Convention in 1848, in which Elizabeth Cady Stanton famously demanded the woman's right to vote through with a call for the ratification of the 19th amendment (Hewitt, 2012). Most Americans know this feminist movement as being led by Susan B. 
Anthony and Elizabeth Cady Stanton and consider its end on November 2, 1920. When women, for the first time in American history, were granted the right to vote for either Republican candidate Warren G. Harding or Democratic candidate James M. Cox. Through this historic vote, women helped determine the 29th president of the United States (Freidel \& Sidey, 2006). This event hallmarked an achievement of more equality between the sexes since both were granted the same right under U.S. law.

While the Women's Suffrage Movement is best known for gaining American women the right to vote, other women's rights leaders and issues surfaced into the mainstream consciousness during this time. Therefore, we should not limit this initial American feminist movement to only the right to vote. Margaret Sanger, a nurse, and birth control activist, opened the nation's first birth control clinics starting in 1916, which evolved into what is now known as Planned Parenthood (Buerkle, 2004). Another leader, Sojourner Truth, a women who escaped slavery, shaped both the abolitionist and feminist movements with her speech, "Ain't I am Woman," which described both free and enslaved black women's experiences during this time period (Truth, 1992). Additionally, Emma Goldman, a Russian Jewish immigrant, was known for challenging gender norms, capitalism, and standard political norms during the first part of the 20th century (Goldman, 2017). While these leaders and issues are not as well known in mainstream America's historical consciousness, they were vital to shaping future feminist movements. These women's efforts went beyond promoting male 
and female equality and pushed for society's adoption of certain ideals about social constructs that both men and women can hold.

The next major wave in America's feminist movement, sometimes referred to as the liberal or socialist feminist movement, is considered to hit its shores in the 1960’s (Peterson \& Lewis, 2001). Betty Friedan's 1963 seminal piece “The Feminine Mystique" calls for an upheaval of the traditional woman's role as husband-pleaser and child-caretaker. She cries out for women to leave their housewife lifestyles for careers, higher education, rights, independence, and opportunities. During this time, feminism was commonly defined as, "The set of beliefs and ideas that belong to the broad social and political movement to achieve greater equality for women" (Fiss, 1994, p. 413). Women seeking to hold positions that men traditionally held was an effort to seek more equality between the sexes.

This understanding, however, is considered a limited view of the feminist movement during the 1960's and the decades to follow. The assumption that most women during that time were primarily housewives whose responsibilities consisted of taking care of the kids and making supper for their husbands described mostly middle class white women's experience. Friedan's notions of a typical American woman did not necessarily resonate with women of color, those in poverty, or those from diverse cultural backgrounds. Some women were already in the workforce, and did not have the option to attend college (Hewitt, 2012). 
During this time, other feminist movements emerged lead by black, Chicana, Asian-American, and lesbian leaders. These movements campaigned for welfare and economic rights. The most notable event at the time was, the passage of the Equal Rights Amendment by the Senate in 1972, which states, "The equal rights under the law shall not be denied or abridged by the United States or by any state on account of sex" (Francis, n.d.). Working class women and women of color played pivotal roles during this time in pushing sexual harassment and workplace discrimination policies nationwide (Hewitt, 2012). These efforts fought against discrimination and harassment sought to change social contracts and for both men and women.

These feminist movements of the past focused mainly on equal rights and the inclusivity of women. Since that time, a newer wave of feminism emerged known as postmodernist or poststructuralist (Peterson \& Lewis, 2001). Feminist philosophers have come out challenging society's understanding of sex and gender. Biological sex determines if a person is a male or female and gender is the social qualities that are assigned based on sex (Scott, 1986). Judith Butler (1988) characterizes gender as a series of acts that create society's understanding of women. To state the concept in basic terms, "One is not born, but, rather, becomes a woman" (Beauvoir, 2011, p. 283). Society determines who becomes a woman by one's actions, movement, gestures, and decisions. This means that gender is a social construct, not a biological fact, and 
as a result gender assignments create inequitable opportunities and consequences for the sexes (Wood, 2010).

This notion of separating sex and gender has brought a new and wider view to feminist activism. Critics of past feminist movements often note that those movements made the assumption that every female has a similar unifying experience. However, feminist leaders of color or those who differ in gender or cultural identity did not necessarily connect to just one narrow narrative of a woman's life experiences. Since this time, the feminist movement has transformed to reach a broader population of people, with the intent to affirm and connect to those who experience and/or resist oppression in a variety of ways (Hewitt, 2012). Postmodernist/Poststructuralist feminists note that a person's identity is continuously changing and growing with multiple identities. Because of this a person can hold the identity as a women, lesbian, doctor, and immigrant all at the same time. However, each of those identities can hold different importance based on her context (Butler, 1990). Holding multiple identities aligns with the feminist point of view that challenges social constructs and allows for everyone to participate in the feminist movement.

\section{Liberal Feminism}

Liberal feminism is defined as the belief that women experience suppression in society because they suffer from injustice and discrimination (Jagger, 1983). Liberal feminists focus on women's experiences with social limitations in employment, discrimination, and access. This movement arose with Mary 
Wollstonecraft in the late 1700's but did not gain momentum until much later in the 1800's. During this time, women did not fit into the public world because of the common held belief that they were not "fully human". Rather, it was thought that women were unworthy of education and access to political power. Because of this women were treated as separate from men and were only allowed to pursue education in fields such as music, sewing, or in order to enhance their companionship and servitude towards men. On the other hand, men pursued educational avenues that included legal power and political participation (Cirksena, \& Cuklanz, 1992). However, liberal feminists argued that women needed to be in the public with political power so that they could contribute to the religious duty of being a representative of God's moral compass spreading the message about right and wrong (Campbell, 1989).

At the time, liberal feminists felt it was necessary to be legitimized in the political process in order to function as free and equal participants in a democracy (Elshtain, 1981; Okin, 1979). Today, women are primarily viewed as worthy of education and are participants in political and power structures. They are considered competent for most lines of work. While many of the issues earlier feminists struggled with have been addressed, patriarchal structures are still in place throughout society which limit women's equity. Workplace pay, loss of power and position when having children, objectification, and violence are all common obstacles women face in modern society. Additionally, liberal feminist advocacy does not explain the underrepresentation of women in positions of 
power and incidents of inequities beyond education and public position

(Cirksena, \& Cuklanz, 1992).

\section{Cultural Feminism}

Western philosophy believes that the mind and the body are separate entities. The body is something that connects us to nature: it is animal and primitive. On the other hand, the mind is intellectual and can outwit and defeat nature. Subsequently, cultural feminists believe that Western philosophy's outlook on how humans interact with the world is problematic for women because of the way gender is shaped and viewed through language and media. Language that is synonymous with women is socially constructed to connect to physical beauty, sexuality, or child-bearing capabilities. Terms such as chick, babe, honey, and doll all connect with physical characteristics. This demonstrates the view that women's connection is to nature and is in opposition with the intellectual world. Thinking about words with masculine counterparts like "Sir-Madam" and "Master-Mistress," we find that the masculine terms of the titles are neutral in physical interpretation, while the feminine terms associated with sexuality. This linguistic structure allows for men to be connected with other activities such as culture, art, finance, industry, and politics while women become tied to their physical form, thus disconnecting them from intellectual activities (Cirksena, \& Cuklanz, 1992).

Cultural Feminists challenge these social constructs of gender and how they shape our understandings of gender and people. They assert standpoint 
epistemology to shape our understanding of people and the world. Standpoint epistemology is the belief that different people have different experiences and create different understandings based on those experiences. We need to acknowledge that people's cultural traditions, personal experience, and societal position influence how we gather and interpret knowledge in the world. Considering these factors account for how two people can experience the same event, situation, or activity and take away different lessons and meanings (Cirksena, \& Cuklanz, 1992).

\section{Feminist Values/Orientation}

The most modern wave of the feminist movement attempts to reach an even broader perspective than its predecessors. This movement draws connections between peace and social justice to end sexism and oppression. Activists in the movement must utilize intrapersonal, interpersonal, societal, and global means to end oppression for all who experience it, regardless of background, which includes gender, race, and economic status. (Hooks, 2015; Zimmerman, McDermott, \& Gould, 2009). This concept is referred to as intersectionality, which links the relationships between gender, class, race, and ethnicity and other social divisions and helps people better understand, resist, and respond to societal oppression. (McCall, 2005; Yuval-Davis, 2006).

This movement has sought to become purposely ambiguous, actively embracing intersectional identities and causes, and welcoming fluid exchange of ideas. Modern understandings of feminism allows more men to take part in the 
movement because the movement challenges larger systems that both men and women can reform. In past movements men were seen as antagonists, which prevented them from being agents of changes (Marchant, 1995). Current feminist movements acknowledge that most men are also disturbed by institutionalized sexism, hatred, and violence against others because of gender, class, race etc. These movements aim to create a community where both females and males are allowed to be self-actualized and live out dreams of a free and just society (Hooks, 2015). This research takes this present-day view of feminism as its conceptual framework.

In order to achieve a feminist society in which diverse groups of people care for and collaborate with one another to solve problems, there are certain orientations community members must agree upon and value. Communities must first acknowledge and affirm that our personal reality is not everyone's reality (Reuman \& Anzaldúa, 2000). To assume that one entire demographic group, such as women, holds a universal experience excludes those who do not fit into that myopic point of view. Also, groups must engage in inclusive dialogue that focuses on raising consciousness of others' diverse experiences. They must reform patriarchal structures to create an environment that seeks to understand all community members (Hooks, 2015; Reuman \& Anzaldúa, 2000). Bell Hooks (2015) visualizes this in her book Feminism is for Everybody, "Imagine living in a world where there is no domination, where females and males are not alike or even always equal, but where a vision of mutuality is the ethos shaping our 
interaction. Imagine living in a world where we can all be who we are, a world of peace and possibility" $(\mathrm{x})$. This demonstrates the collective dreams and ambitions feminist philosophy hopes to bring to society.

This modern wave of feminism is not longer satisfied by women merely having a seat at the table. This wave is focused on fundamental shifts in how we live together in society. To understand how such a shift is even possible requires us to decouple gender from sex. Feminism has ceased being understood as a limited spectrum of people assigned to a certain sex. It's focus has become broader, reaching out like a web to all communities because it's focus is on including everyone to develop communities of mutual respect, celebration, and problem solving.

\section{Hypermasculinity and Patriarchy}

The divergent philosophy to feminist thought is often referred to as masculinity, hypermasculinity, hegemonic masculinity, or patriarchy. It's important to review the norms and values of this orientation, so that we can understand what feminism is not. Patriarchal structures and hypermasculine values in society are those that grant certain institutional opportunities or privileges to the group in power. This group is often composed of, but not limited to white, heterosexual, middle class men (Messner, 1997). Women and those from other backgrounds can also hold these values. Hypermasculinity often reveals itself in those who find virtue in violence, danger, and careless sexual attitudes. People who value masculine norms respond favorably to reactions 
such as excitement and anger. They view distress and fear as weaknesses (Mosher \& Tomkins, 1988).

In the school setting hypermasculinity can manifest itself in many ways. When a teacher who values patriarchal structures teaches students, they project certain principles in the classroom. They often believe that students of color or those from struggling socioeconomic backgrounds have the same opportunities, if not better, as their white middle-class peers. Richardson (2012) interviewed a group of teachers who held hypermasculine values. One teacher stated, "I think these black and Spanish (Latino) kids don't realize what they got going here. I remind them all the time that they got it good. That if they want to go to college all they gotta do is get good grades and do other things like be active in sports. And they got themselves a free ride" (50). This sentiment demonstrates a narrow screwed view of opportunities for students of color. It fails to acknowledge challenges their families and communities systematically face in their daily lives.

They teach curriculum that solely prepares students for tests and focus on knowledge that connects with groups in power that benefit from the patriarchy. Hypermasuline teachers put an overwhelming amount of merit into standardized test scores. Teaching only skills and content necessary for high marks on the test. This results in teachers feeling competitive instead of collaborative towards one another (Richardson, 2012). Richardson (2012) attempt to explain, "If you and I are both $5^{\text {th }}$ grade teachers... we would be in direct competition. It becomes more difficult, then, for you and me to help each other out" (31). 
The patriarchal teachers see themselves as the expert and holder of the knowledge, dispensing education to students, like a banker distributing money to their patrons (Freire, 2000). Because they view themselves as high priests of knowledge, this approach drives out other opportunities for a variety of learning experiences and uses a one size fits all method in the classroom (Griffiths, 2006). They tend to see the world from a narcissistic point of view, and often believe that they are the leading authority on teaching. They believe they already have ultimate control in their classroom and therefore dismiss opportunities for professional development and collaboration with peers (Richardson, 2012).

This group often frames boys as "new" victims in the education system. They blame women teachers and feminist pedagogy for the problems boys face in society. These educators think female teacher are the reason for boys' underachievement and recruit male teachers to re-masculinize schools. They believe that eliminating female teachers will result in more boy-friendly schools (Martino \& Kehler, 2006). They see female students performing better in school as a threat to maintaining the patriarchy.

Hypermasculine peer-to-peer conversations regularly focus on sexual exploits, sports, alcohol consumption, or technology for entertainment. Richardson (2012) writes about a group of hypermaculine teachers causally talking, "Sports, beer, women, and sex are woven seamlessly throughout the conversation for men. Masculine narratives typically dominate these topics, regardless of context" 
(88). The hypermasculine group usually shuns those teachers who do not feel that these topics are worthwhile (Richardson, 2012).

\section{Feminist Classrooms}

Feminist pedagogy encompasses a myriad of strategies rooted in the beliefs and values of the movement. This often comes to life in acts of intersectionality that brings groups of diverse people together that care about an issue to create a positive change. The purpose of this research is to show a correspondence between NBPTS and feminist pedagogy. Even though the standards do not encompass all qualities of feminist pedagogy, pedagogical characteristics from the NBPTS do intersect with feminist pedagogy. This research will identify and analyze those points of intersection by showing how the following three feminist values govern both the pedagogical philosophy the NBPTS espouses and the teaching practices they advocate. Those values are also central to the understanding of relationships and content that the NBPTS encourages.

Care. Caring about others' emotional state is a common theme that arises in feminist pedagogical literature (Hooks, 1994; Johnson \& Bhatt, 2003; Kazemek, 1989; Kishimoto \& Mwangi, 2009; Musial, 2011; Noddings, 1992 \& 2008; Regan \& Brooks, 1995; Spencer, 2015). Caring can be defined as having a fondness for the world and the people in it and developing a commitment to morally act on the behalf of others (Regan \& Brooks, 1995). A student's emotional state can greatly impact the ability, willingness, and conditions in which they learn (Hooks, 2010). This is why listening, paying attention, and responding to students needs 
is imperative in the classroom (Noddings, 2008). For transformative education that consciously changes a student's worldview to take place, students need to feel comfortable enough to discuss topics that make them feel vulnerable. This makes trust between teacher and student and amongst classmates a necessary component of feminist pedagogy (Kishimoto \& Mwangi, 2009).

Recently, education has shifted to rely on standardized tests and technology for students to determine, create, and demonstrate understanding and knowledge. However, this change does not account for students' emotions. Creating classrooms that rely on listening, thinking, and questioning foster an environment for the mind, body, and emotional spirit to more readily learn (Hooks, 1994; Musial, 2011). Students bring with them emotions that come from outside relationships, life experiences, and traumas that shape them. Being able to positively respond to students' affective state such as pain, joy, frustrations, or the spectrum of other emotions helps teachers create caring environments that foster learning (Musial, 2011).

To create these emotionally responsive conditions a teacher must avoid hierarchical notions of being the sole holder of knowledge and moral compass. They must see themselves as connected to each student like a link in a chain, responding to them with care and compassion while fostering their classmate to do the same (Belenky, 1986; Kazemek, 1989; Noddings, 1984). This can be achieved by the teacher having the students make the rules and norms for a caring classroom. When the students are given some of the 
power to determine the classroom environment, the hierarchical dynamics between teacher and students are reduced (Johnson \& Bhatt, 2003).

The classroom must also focus on students' relationships between each other and how they fit into the outside world. They must be provided opportunities to explore their own personal identities and connect that with their personal moral agency. The teacher provides students the opportunity to see how culture and politics distract us from noticing injustices in society. This then gives students the opportunity to be outraged by injustices in society and the means to act with care and morality when facing injustice throughout their lives. With this transformative environment, students foster personal relationships based on caring, justice, and peace rather than relationships based on social status (Hobgood, 2012).

Feminist teachers build relationships that reflect care and concern when working with colleagues. This involves helping and supporting others by growing an environment they need in order to progress in their work. Furthermore, they ensure that their interactions with others lead to trusting relationships. When teachers build and model caring relationships with other adults at the school, it gives those adults permission to form more caring relationships amongst their peers. This can create a positive cultural shift in the way staff relates and connects to each other (Regan \& Brooks, 1995).

Diversity. The word diversity is ubiquitous in feminist pedagogical research (Gardner, Dean, \& McKaig, 1989; Griffiths, 2006; Kazemek, 1989; Kishimoto \& 
Mwangi, 2009; Musial, 2011; Spencer, 2015; Watson, 2008). Diversity is defined as differences based on social categories like gender, race, sexuality, class, and others (Adams, 2013). When teaching others the definition expands and is also interpreted as the avoidance of standardized teaching practices and the implementation of a variety of teaching practices used to demonstrate how we and society benefit from human differences (Griffiths, 2006).

Most students learn from an early age to respond to human difference through what is known as a patriarchal consciousness. This means they see traits, skills, and talents as superior/inferior or dominant/subordinate relationships. Viewing people in this way leads to responses of fear and distorted understanding of others (Gardner, Dean, \& McKaig, 1989; Lorde, 1980). This means teachers must redefine difference as strengths, creativity, and power and relate to one another as equals (Gardner, Dean, \& McKaig, 1989).

To accomplish inclusive diversity in a feminist setting, we must acknowledge that there are power differences in society and some groups have certain advantages and some groups have certain disadvantages (Spencer, 2015). Simply having a diverse community of students is not enough (Hobgood, 2012). Teachers must minimize those patriarchal constructs in the classroom by honoring difference and creating a collective construction of knowledge in the classroom setting (Gore, 1993; Lee, Ming-yeh, \& Johnson-Bailey, 2004; Mogadime, 2003; Welch, 2006). This comes about through discussion about our own diversity, relationships, and feelings about various groups (Chang, 2002). 
The teacher must guide the students to analyze and critique the community's structures of power and success (Hobgood, 2012).

Feminist teachers recognize that students are negotiating their sense of selfidentity in the classroom and they attempt to cultivate the best parts of their students. This is achieved when teachers minimize competition in the classroom. Direct correction sets students up to believe that there is only one right way of doing something, or that they are wrong and faulty. Feminist teaching instead guides students to create a more meaningful, honest, or expressive understanding that can build a stronger safer classroom environment that embraces diversity (Musial, 2011).

A teacher acknowledging, embracing, and encouraging diversity and individual identity helps students go beyond just forming intellect to transforming their consciousness of how they see themselves, others, and interactions with society (Kishimoto \& Mwangi, 2009; Weiler, 1988). Teachers building these relationships with students and among their peers will strengthen our democratic society by allowing more groups to bring forward their talents to contribute to the broader community (Kazemek, 1989).

Collaboration. Collaboration is a foundational aspect of feminist pedagogy. This applies to teachers facilitating student-to-student learning and teachers reflecting and building on their own teaching practices (Gardner, Dean, \& McKaig, 1989; Kazemek, 1989; Regan, \& Brooks, 1995; Sykes, 1996; Thurber, \& Zimmerman, 2002; Watson, 2008). Collaboration can be defined as, "The 
ability to work in a group, eliciting and offering support to each other, creating a synergistic environment for everyone" (Regan, \& Brooks, 1995 p.26). Valuing collaborative practices that build and grow knowledge is a method for creating caring classrooms that appreciate and affirm diversity.

Student collaborative models can take several forms with the focus to connect networks of students in order to nurture responsibility towards one another rather than competition. Teachers facilitating activities that allow students to interact with one another in cooperative, caring ways promotes a collaborative classroom culture (Kazemek, 1989). One way teachers can lead this type of collaboration is through creating imaginative roles or "plays", to explore moral

possibilities. Students are given the opportunity to practice and participate becoming upstanders and also get to critique their peers responses to acted-out situations. This can be a useful model and tool for students as they navigate the world and face moral dilemmas (Boal, 2001).

When leading classroom discussions the teacher should not be the holder of knowledge, but cannot be a passive participant in the process either. They must provide structures in which to facilitate students sharing their own knowledge and understanding. The teacher must show students how to use their knowledge for empowerment, and not to exercise power over others. This will help teachers avoid hierarchical classroom dynamics. These structures take a deliberate effort for the teachers to highlight collective responsibility in the classroom (Gardner, Dean, \& McKaig, 1989). Giving individuals who are speaking a space to have 
the floor where they are free from interruption and the opportunity to choose the next speaker is one strategy that feminist practitioners use. With this technique, teachers provide guidelines for students letting them know that their grade is based on sharing the talking space and allowing all to have their voices heard. Those who use evidence relevant to the context of the class score higher points than those who base their comments on personal opinion (Watson, 2008).

Amongst fellow staff members, feminist teachers are engaged in collaborative practices. Collaboration is considered the foundation to feminist professional leadership (Thurber, 2005). We find that far too often teachers are the targets of reform and are not educational reformers themselves (Sykes, 1996). To shift this paradigm, it is necessary for feminist teachers to use their voice to build relationships and create change. Collaboration allows for opportunities for group empowerment, using others' strengths to accomplish broader culture-changing goals (Thurber \& Zimmerman, 2002). Far too often teachers are given "one-shot" workshops with the expectation of implementing a new teaching strategy that may not be relevant to their students or supported by other school leaders (Sykes, 1996). However, feminist teachers who see themselves as change agents and build trustworthy friendships where there is a commitment to exchange of instructional ideas to inform pedagogy make lasting impacts on their school communities (Thurber \& Zimmerman, 2002).

Effective teacher collaborators ask for help and bring colleagues together. They build leadership capacity in their peers which give their peers 
self-efficacy and empowerment in their school community (Regan \& Brooks, 1995). Successful collaboration practices involve inclusiveness and shared ownership. We can imagine feminist teacher leaders as the center of things reaching out like a web connecting to others in place of a hierarchically patriarchy where the top reaches downward to set mandates and initiatives. (Helgesen,1990).

\section{An Overview of the National Board for Professional Teaching Standards}

This study aims to show that care, diversity, and collaboration are central to the teaching standards espoused in the national board. The following section provides a brief history of the national boards to demonstrate the significant weight given them within the teaching profession. The idea of national teaching standards were birthed in response to the 1983 report, "A Nation at Risk", which claimed our nation's public schools were failing and they must be reformed (Cannard, 2017). Soon after this report the Carnegie Corporation created a Task Force on Teaching as a Profession. This group was tasked with creating professional development for teachers through new national standards for the teaching profession. This action was significant because the idea was being proposed by the neither government nor teachers unions.

The Carnegie Corporation determined that teachers would be able demonstrate that they could effectively assess students' knowledge. This teaching practice would be guided and aligned with standards set by both national and state governments (Darling-Hammond, 1999; O'Day \& Smith, 
1993). It also required teachers to actively participate and engage with broader community agencies to help support students. Additional involvement with parents and student's families became a necessary component to complete the certification (Darling-Hammond, 1999).

The Carnegie Corporation's vision is that "Board-certified teachers are identified by habits of the heart, as the kinds of human beings whom we trust and to whom we entrust the children of our communities. We trust them to use their knowledge and skills for the benefit of their students, their communities, and their society." (National Board for Professional Teaching Standards [NBPTS], 2016 p. 5). The NBPTS are written by classroom teachers, which is a hallmark of any professional standard. Those who are currently working as doctors write similar standards for practicing doctors. The Carnegie Corporation considers achieving National Board Certification the highest honor in the profession and in my ten plus years of personal experience as a classroom teacher, I have yet to see that notion challenged within the profession (NBPTS, 2016).

The certification process. Teachers with at least three years of teaching experience and a bachelor's degree are eligible to voluntarily apply for National Board Teaching Certification (Gitomer, 2014; Belson, Husted, \& Irvine, 2015). Most states offer a salary bonus for completing the certification that ranges between $\$ 1,000$ and $\$ 10,000$. The states with these bonuses typically have more teachers with the certification. The goal of the program is not only to provide teachers with the instructional skills to improve student achievement, but 
also develop leadership qualities in certified teachers. This program is unique in that it is the only teacher certification program in the country that requires teachers to engage in collaboration with their colleagues. The purpose of this is to spread teacher professional development across the school campus and build a network of professionals willing to help one another grow in their instructional practice (Irvine, Belson, \& Husted, 2015).

To obtain the National Board Teaching Certification, teachers engage in a rigorous one to three year process. The work is portfolio based and has four performance based entries and six assessment based exercises. These tasks require the applying teacher to show their students' work, videos of their classroom teaching, and evidence of their professional work with others. This comes in form of teacher professional development, colleague collaboration, community outreach, and connecting with parents. The entire process requires the teacher to: describe their classroom, students, and community, deeply examine their teaching practice, strategies and pedagogy, and reflect upon their decisions and choices as a professional. This year requires between 150-200 extra work hours and the certification requires a smaller renewal process once every ten years (Cannard, 2017).

National boards background. The National Board Certification process is the most ubiquitous and highest regarded teacher certification process in the United States. With 25 certifications, teachers of all grade levels and subject areas can obtain certification. After more than thirty years since the NBPTS inception, more 
than 112,000 teachers across America have received their certification. However, the National Board for Professional Teaching Standards set these standards without empirical evidence that teachers who achieved these standards were superior (Vandevoort \& Berliner, 2004). This is challenging because teaching happens in such varied context, which has made determining how much of an impact the National Board Certified Teachers have on student success compared to those without the certification a daunting task (Gitomer, 2014).

Only about $3 \%$ of all teachers have earned Nationally Board Certification, which limits the number of teachers available to conduct most research (Irvine Belson \& Husted, 2015). These teachers are spread throughout the United States, some working in schools with colleagues who also have earned the certification and others who are the only teacher on staff certified. These teachers' grade level, content area, student population, and class sizes are as diverse as America itself. Factors teachers cannot control such as schools settings, programs offered, resources available, public, private, and charter all have an impact on student success. This is why the research available on the effectiveness of teachers with the certification is inconclusive (Gitomer, 2014).

While it is important to acknowledge this variation and inconclusive evidence on the effectiveness of the certification, the standards' impact on student success will not be taken into consideration for this research. This research will be interpreting text of the NBPTS through feminist interpretive inquiry. While the debate still persists about the NBPTS impact on students, most are not debating 
that these standards are held in high regard throughout the profession. This can be proven by the high number of states that offer extra salary for teachers who receive the certification and the additional level of prestige given to those who earn the certification (Irvine, Belson, \& Husted, 2015). While researching the NBPTS I found many resources that attempted to determine the validity of the standards. However, there is a scarcity of independent research about the historical development of these particular standards. This section provides historical background on the development of the standards as described in "What Teachers Should Know and Be Able to Do" released by the NBPTS (2016). This history supports my claim that the NBPTS represents general agreement about best practices in the profession.

In 1985, a few years after the publication of the "A Nation at Risk" report, the Carnegie Corporation established a Task Force on Teaching as a Profession. This group brought together a small group of scholars in the field of education, led by Lee S. Shulman, and American scholar and education physiologist, to write a proposal describing what a National Board for America's teachers would look like. This was a unique task in that no governmental or union agency would be involved in the effort. The group developed a proposal outlining standards and assessments for classroom teachers in America.

During this time many professions had already established board certifications. For example, doctors and architects had long been held to national standards of excellence. Many did not consider teaching a profession and 
questioned the necessity for national standards. In the international community, many could not imagine creating national standards without a governmental institution's involvement. This initial skepticism and lack of buy-in from the professional community made it challenging for the NBPTS to be taken seriously by the broader community.

As the project developed teacher leaders were enlisted to help develop the program, between the years of 1985-1990. Their focus was to ensure the NBPTS would have a positive influence on the professional development of teachers across the nation. This required portfolio development, assessments, and coaching that allowed for professional reflection to improve the quality of their teaching practice. The standards have been revised once, in 2015 to mirror advancements in the field of research, and practice. With the help of 700 National Board Certified teachers, modern updates like the integration of technology and change of language were welcomed additions to the text.

Other significant teaching standards. It should be noted that there are other documents in the field of education that attempt to function similarly to the NBPTS. They are viewed as guiding documents for teaching professionals. These documents are released by governmental organizations, professional associations, and teacher unions. This section will discuss a couple of notable examples. During the aughts, the first decade of the $21^{\text {st }}$ century, the U.S. Department of Education released guidelines for "Highly Qualified Teachers" 
under the No Child Left Behind Act. In 1975 the National Education Association adopted a "Code of Ethics" for those in the field of education.

The No Child Left Behind Act required that K-12 public schools hire "Highly Qualified Teachers" to serve in their classrooms. The U.S. Department of Education website states, "Highly Qualified Teachers: To be deemed highly qualified, teachers must have: 1) a bachelor's degree, 2) full state certification or licensure, and 3) prove that they know each subject they teach." This is defined in a two-page fact sheet document titled "New No Child Left Behind Flexibility: Highly Qualified Teachers -- March 2004". This fact sheet lays out expectations for classroom teachers. Like the NBPTS, the fact sheet attempts to explain what a teacher should know. In contrast to the NBPTS, the fact sheet focuses mostly on educational requirements such as certifications, degrees, and tests a teacher may need to pass or earn in order to be considered a Highly Qualified Teacher. The document is significantly shorter than "What Teachers Should Be Able to Know and Do" and it does not address pedagogical practices a teacher may employ in the classroom.

The National Education Association is the U.S.'s largest teachers' union. Through a representative assembly of national teacher leaders, they adopted a "Code of Ethics" (n.d.). This code is also about two-pages in length, and has three sections: a preamble and two principals. The "Preamble" portion of the document describes the ethics an educator must hold in four brief paragraphs and outlines what educators should believe about students, 
classrooms, and their teaching practice. The "Principals" portions of the document explains commitments to students and the profession. These are written in a series of eight statements starting with the phrase "In fulfillment of the obligation to the profession, the educator-- shall not..."

Both the National Education Association's "Code of Ethics" and "What Teachers Should be able to Know and Do" provide a set of expectations for teachers. However, these documents differ because the "Code of Ethics" focuses on what teachers should not do, while the NBPTS goes to great lengths to demonstrate what teachers should do. One of the goals of the "Code of Ethics" is to serve as an internal disciplinary document. The last line of the Preamble states, "The remedies specified by the NEA and/or its affiliates for the violation of any provision of this Code shall be exclusive and no such provision shall be enforceable in any form other than the one specifically designated by the NEA or its affiliates."

There are still other documents in the field of education that outline expectations for teachers. Their purpose greatly varies based on who writes these documents and for what intended reason. "What Teachers Should be Able to Know and Do" holds relevant significance to the profession because it is not intended for just one agency's specific use regarding basic requirements of the profession. It is intended to set a bar of excellence for every teacher in the profession. It's a document that details ideals for professionals in the classroom setting as an exemplary example towards which others should strive. This gives 
the NBPTS the weight to hold such great significance in the profession, and is the reason why it's worth closely examining. 


\section{Chapter 3 Methods}

\section{Research Objective}

In chapters one and two, I establish three key values shared by different feminist pedagogies: care, diversity, and collaboration, and I define each term by compiling key ideas from different feminist pedagogical research. These three values were chosen because they are recurring themes throughout the feminist pedagogical literature. However, these are not the only values feminist instructors hold, nor do they hold superiority over other feminist values. These values were chosen because they are consistent in both the feminist literature and throughout the FCP in the NBPTS. The objective of my analysis is to show the extent to which the FCP espouses those same values and in doing so establish common ground between mainstream pedagogical discourse and feminist pedagogy. Because these standards are ubiquitously held in high regard throughout the teaching profession in the United States, offing a feminist

interpretation of the standards can reframe way we think about K-12 pedagogical practices. Twenty first century classroom teachers should rethink and aspire to what role, if any, gender identity should play in the profession.

The focus of this study is a single artifact that is representative of mainstream educational discourse: a fifty-two-page booklet issued to potential applicants by the NBPTS titled "What Teachers Should Know and Be Able to Do." According to the NBPTS website, in December of 2016, the NBPTS released a revised version of "What Teachers Should Know and Be Able to Do," which can serve as 
part of the teaching profession's core body of knowledge. The book, which explians the FCP for teaching, "is similar to medicine's Hippocratic Oath, held in common by all teachers of all grade levels and disciplines and underscoring the accomplished teacher's commitment to advancing student learning and achievement" (NBPTS, 2016, p. 8). Because it is so highly regarded by the organization and within the field and is compared to the ethical oath doctors take before embarking on their medical practice, this book holds strongly weighted perspectives on the profession. These core propositions are considered to be the teaching standards themselves. The propositions and explanations are representative of mainstream educational discourse and express the expectations we hold for all classroom teachers regardless of their gender. I conducted close reading of "What Teachers Should Know and Be Able to Do" and the FCP written by the NBPTS along with their extended explanations. This shows that they are also representative of feminist values and in counter to patriarchal values. More specifically, the FCP advocates care, diversity and collaboration in all aspects of teaching. It does not endorse pedagogical practices that promote systems of oppression, domination, or exploitation, nor does it promote standardization, competition, or hierarchal thinking. In showing a correspondence between feminist pedagogy and the FCP, I am acting the role of what Condit (1993) calls the "empathic critic" who locates "pieces of common ground among various voices...to discover options for those compromises necessary for co-existence (189). This approach aligns with feminist research 
practices that aim to identify "positive communication practices and role models. These 'reconstruction' strategies [attend] to positive identity formation and to the building of relationships that are consonant with feminist values" (Dow and Condit, 2005, p. 462).

\section{Feminist Discourse Analysis}

Discourse analysis can be defined as, "The study of how sentences in spoken and written language form larger meaningful units such as paragraphs, conversations, interviews, etc." (Richards \& Schmidt, 2013, p.174). A close reading of a specific representative text can show the strategies and forms that govern a particular discourse, such as teacher training and professional standards. Feminist discourse analysis, a form of feminist interpretive inquiry, shows how a discourse aligns (or does not align) with feminist values and practices. The point of this analysis is not to prove a feminist intent, but to identify resources that model feminist thought and can be referenced when advocating feminist values. In the case of a text that is representative of a prominent discourse, such as the FCP, feminist analysis can show feminist thought as more central and influential than might be presumed. This kind of analysis helps to displace patriarchal thinking as the status quo.

Discourse analysis differs from interpretive methods that aim to reveal the meaning of a text or an author's intent (Gavey, 1989; Van Dijk, 1985). This research will not claim that the FCP were written with a feminist pedagogical intent. Without interviewing the author of a text it is impossible to know a writer's 
true intent of a piece. However, examination of the language of the text and word choice shows empirical evidence of overlap between the philosophies and practices espoused in the NBPTS and aspects of feminist pedagogy. Like McGee (1980) points out, "If a mass consciousness exists at all, it must be empirically 'present,' itself a thing obvious to those who participate in it, or, at least, empirically manifested in the language which communicates it" (4). Meaning, we may not be able to see what is in this case "feminism" however we can communicate its structures. A close reading of passages and notable phrases from the FCP highlights patterns of language consistent with feminist pedagogical approaches (Gavey, 1989).

This analytical approach does not have one prescriptive method (Potter \& Wetherall, 1987). My approach focused on the presence and absence of specific values and highlights language that is representative of those values. I have explained what feminist pedagogy is and shown care, diversity, and collaboration to be central to it. My analysis found that the NBPTS, too, stresses the importance of caring, diversity, and collaboration in teaching. The NBPTS identifies those qualities as necessary to teachers today. In addition, my analysis found a complete absence of patriarchal philosophies or practices such as standardization and hierarchical thinking. This analysis clarifies what the profession values in teaching practices. A teacher's gender does not feature in those professional values. In place of judging teachers by their gender identity, the NBPTS places more weight on individual teaching practices. 


\section{Research Process}

In my analysis, I identified two levels of commitment to care, diversity, or collaboration. First, those values are present in the NBPTS's teaching philosophy, which is the belief that teachers hold about themselves, students, and the profession. Second, those values are present in the NBPTS's teaching practice, or the specific actions that teachers and students do in and outside the classroom to facilitate learning. It is important to make a distinction between practice and philosophy. For example, a teacher may believe they should never operate in isolation so they schedule weekly collaborations with fellow teachers to help develop and refine their curriculum. Both aspects of philosophy and practice are illustrated in this example. Philosophically a teacher believes they should never work alone. In practice that becomes weekly meetings with colleagues to discuss curriculum, instructions, and other school matters. Throughout the NBPTS text, we see philosophy and practice woven together to create a concise expectation of exemplary teachers and classrooms, and in all cases, care, diversity, and collaboration are central to both philosophy and practice.

When sorting the data into these two categories I developed certain criteria for each category to distinguish statements about philosophy from statements about practice. Statements about teaching philosophy focused on beliefs teachers understand or know to be true. They connect with the teachers' beliefs and attitudes towards a variety of realms in education. This consists of a collection of 
abstractions such a values and ideals a teacher may hold. These philosophical ideals were not just focused on students but also relationships between colleagues, families, and the outside community.

When a statement referred to concrete actions a teacher, student, or other stakeholders could take, I catalogued it under a teaching practice. Statements about teaching practices range from a variety of actions and techniques the teacher employs throughout the day. These actions sometimes happen inside the classroom. It can be a practice that happens while instructing the entire class, small groups, or individual students. A teaching practice may also happen while class is not in sessions. A teacher may take a particular action that would qualify as a teaching practice while planning a lesson, collecting and analyzing assessment data, collaborating with other staff members, connecting with parents, and more.

The text also made significant reference to what students do throughout the learning process. This ranged from how they approach assignments in the classroom to interaction they had with peers throughout collaboration and social times. A quality teaching practice can helped foster and build relationships among classmates and create a community of learners. To achieve this practice both the teacher and students must be active participants responsible for learning process. 


\section{Chapter 4 Analysis}

\section{The Format of "What Teachers Should Know and be Able to Do"}

"What Teachers Should Know and Be Able to Do" is a forty-five page PDF booklet found on the NBPTS website. It functions as a detailed guide for teachers who are earning or considering earning National Board Certification. The booklet opens with a five-page preface that gives a historical narrative about the birth of the NBPTS. It is followed by a two-page introduction that provides some general philosophical approaches to the NBPTS. Then, pages ten through thirty-nine give a detailed explanation of the FCP and their subheadings. Finally, the last five pages of the document is a conclusion that explains the NBPTS implications for the teaching profession.

The booklet outlines the habits of mind an outstanding teacher must demonstrate. It focuses on a variety of aspects of teaching, such as knowledge, strategies, subject matter, skills, and more. Furthermore, it stresses the importance of habits of heart. The standards challenge teachers to think about themselves as people society entrusts to our children and they ask teachers to develop children into the kind of human beings we should strive to be. These objectives are made clear in the following statement that opens the booklet: "Through National Board Certification, the National Board for Professional Teaching Standards seeks to identify and recognize teachers who effectively enhance student learning and demonstrate the high level of knowledge, skills, 
abilities and commitments reflected in the following Five Core Propositions" (NBPTS, 2016, p.10)

The booklet is structured for teaching training and centers on the FCP. The Five Core Propositions are:

1. Teachers are Committed to Students and Their Learning.

2. Teachers Know the Subjects They Teach and How to Teach Those Subjects to Students.

3. Teachers are Responsible for Managing and Monitoring Student Learning.

4. Teachers Think Systematically About Their Practice and Learn From Experience.

5. Teachers are Members of Learning Communities.

The NBPTS also defines what they believe a teacher represents. The booklet states:

As teacher we use the many sources of professional knowledge, skill and experience at our disposal to engage the minds and hearts of children and youth by teaching and inspiring them. And once we mess with minds and hearts, we are prepared to take responsibility for the messes we have brought to life, the prejudices we have forestalled, and the society to which we have given hope." (Shulman, 5)

This definition then obligates teachers to be skilled, ethical, self-aware, empathetic professionals that are responsible for themselves and others.

These ideals and mission are outlined in the introduction of "What Teachers Should Know and Be Able to Do."

- maintaining high and rigorous standards for what accomplished teachers should know and be able to do; 
- providing a national voluntary system certifying teachers who meet these standards; and

- advocating related education reforms to integrate National Board Certification in American education and capitalize on the expertise of National Board Certified Teachers. (NBPTS, 2016, p. 8)

My analysis focuses on the FCP found in pages ten through thirty-nine. Each proposition is laid out in three to six pages of text. Each proposition begins with a dedicated title page of a clearly phrased one-sentence expectation for teachers. This is followed by a small introduction on a new page with subheadings that provide more detail about the proposition. Under each of these subheadings is a multi-paragraph explanation of what teachers should philosophically believe and practically do. These explanations are the focus of this entire discourse analysis. While the NBPTS booklet does not provide the concrete numbering for each of these sections, I will be using it throughout the analysis to refer to the section and subsection where the text is found. Below are all the proposition and subheadings within their dedicated sections.

1. Teachers are Committed to Students and Their Learning.

1. Teachers Recognize Individual Differences in Their Students and Adjust Their Practice Accordingly

2. Teachers Understand How Students Develop and Learn

3. Teachers Treat Students Equitably 
4. Teachers Know Their Mission Transcends the Cognitive Development of Their Students

2. Teachers Know the Subjects They Teach and How to Teach Those Subjects to Students.

1. Teachers Appreciate How Knowledge in Their Subjects is Created, Organized, and Linked to Other Disciplines

2. Teachers Command Specialized Knowledge of How to Convey a Subject to Students

3. Teachers Generate Multiple Paths to Knowledge

3. Teachers are Responsible for Managing and Monitoring Student Learning.

1. Teachers Call on Multiple Methods to Meet Their Instructional Goals

2. Teachers Support Student Learning in varied Settings and Groups

3. Teachers Value Student Engagement

4. Teachers Regularly Assess Student Progress

5. Teachers engages Students in the Learning Process

4. Teachers Think Systematically About Their Practice and Learn from Experience.

1. Teachers Make Difficult Choices That Test their Professional Judgment

2. Teachers Use Feedback and Research to Improve Their Practice and Positively Impact Student Learning 
5. Teachers are Members of Learning Communities.

1. Teachers Collaborate with Other Professional to Improve School Effectiveness

2. Teachers Work Collaboratively with Families

3. Teachers Work Collaboratively with the Community

The goal of this chapter is to show that the NBPTS defines accomplished teachers as caring, collaborative, and appreciative of diversity. Those values are presented in every level of the document, from the philosophical approaches it espouses, to the classroom practices it advocates. Each of the FCP articulates both a teaching philosophy and a recommendation for specific teaching practices. In each case, the values of care, collaboration, and diversity are central to both pedagogical philosophy and practice.

In order to show the correspondence between the NBPTS and feminist pedagogy, I organized by combining all the references to care made throughout the booklet, followed by all the references to diversity, and then the references to collaboration. In some cases where the passage makes direct reference to one of those three values, the connection is self-evident. In other cases where the connection is not obvious, I demonstrate how the quote connects to the literature about the feminist value. I also show how each FCP diverges from hypermasculine or patriarchal values and show that such values are absent from the booklet altogether. 


\section{Care}

Caring is defined as having a fondness for the world and the people in it and developing a commitment to morally act on the behalf of others (Regan \& Brooks, 1995). In the feminist literature this most frequently arises in regards to others' emotional state and how that state impacts learning (Hooks, 2010). Care happens when teachers pay attention and respond to students needs (Noddings, 2008). In the classroom, teachers foster environments that prepare both the body and mind for learning in order to progress in their work (Hooks, 1994, Musial, 2011, Regan \& Brooks, 1995). They give students power to determine these environments, and breaking down patriarchal structures is another way in which teachers can demonstrate fondness and care for their students (Johnson \& Bhatt, 2003). This commitment to moral action involves allowing students to explore their own personal identity and moral agency (Hobgood, 2012).

Practice of care. Three out five of the propositions speak to a practice of care. Section 1.2 discusses how students develop and learn. This section focuses on how teachers might connect personally to their students, and in doing so offer students a stronger connection to the content they learn. These connections allow a student to see how the new information is relevant to their lives and to other subjects they study. To achieve what the NBPTS suggests, it is necessary for teachers to learn about the students' lives and then apply their experience to the classwork. This connects with Nodding (2008) who advocates for teachers to listen and respond to students because they take individual experiences into account to make learning relevant. This allows 
students to take control of their own learning needs because they connect content with their lives. The passage reads, "By encouraging students to relate their personal experience to the classroom environment, teachers help students make learning relevant and advance their skills across academic settings" (NBPTS, 2016, p.15).

The third proposition contains three references to a practice of care. Section 3.2 endorses classroom systems that foster positive relationships, and that create safe spaces. These are places where learners can thrive because they are in an environment where they are interested in learning and feel respected by others. This is due to the structures the teacher puts in place. They have deliberate proceedures to ensure learning, safety, and healthy relationships. This aligns with Hooks (2010) writing about feminist classroom environments because the teacher has the ability and obligation to impact the condition in which students learn. Safe spaces that foster positive interaction among learners are examples of these learning conditions. The introduction to the proposition reads:

To increase students' success, teachers diligently manage the systems, programs, and resources that support every educational endeavorfostering positive relationships in and out of the classroom, making sure classroom materials are used appropriately, maintaining schedules, ensuring student safety, and otherwise maintaining all aspects of a wellfunctioning learning environment. As masters of pedagogical practice, accomplished educators teach efficiently, making the most of every instructional moment to maximize learning. They are dedicated to helping young people thrive by respecting, encouraging, and advancing student interests and student learning at all times. (NBPTS, 2016, p. 24)

More examples of the practice of care emerge under Section 3.2 which addresses student learning in varied settings. The NBPTS expects teachers to 
anticipate students' need for support rather than be reactive and controlling about disruptive behavior. In doing so, responsive teachers help students to engage with learning immediately. They predict possible disruptions or distractions beforehand and prepare interventions ahead of time so that classroom time is not wasted. This connects with Musial's (2011) interpretation of feminist teaching technique which requires the teacher to be positively responsive to students' affective states. When teachers bring the focus back to learning after a disruption, they optimize other students' opportunities for learning because the focus is on the lesson not the distraction. The passage states, "The management techniques that accomplished teachers use are proactive rather than reactive, helping classroom participants focus on learning instead of controlling disruptive behavior" (NBPTS, 2016, p. 26).

The last example of the practice of care falls under Section 3.4 which discusses student assessment. This passage shows the NBPTS endorses teachers to allow students to grapple with the frustrations that occur with learning. This means when there is a challenge teachers provide guidance that encourages students to remain focused on the task. This requires a level of care that allows the teacher to acknowledge their feelings, but also pushes them in their new learning. This connects with Noddings (2008) research that says feminist teachers must pay attention and respond to students during frustrating moments to ensure that students have a choice to either stop or continue. The NBPTS say teachers should respond by modeling how a student might move 
forward through their frustration. This requires teachers to listen to students' frustration with the learning and then address that frustration with a opporunity that allows them to continue learning. The passage reads, "Accomplished teachers model strategies for dealing with the doubts that students may experience helping them realize that frustrating moments often are when learning occurs" (NBPTS, 2016, p. 28).

The final example of the practice of care comes in Section 4.2. This section reveals the importance of feedback the teacher gives the student. It also stresses the importance of the positive impacts on student learning. This shows that the NBPTS encourages teachers to forego teaching the standard curriculum when there may be a relevant classroom opportunity to build relationships. This is much like with Nodding's (2008) feminist approach which endorse teachers listening, paying attention, and responding to students. To foster relationships the teacher and student must pay attention to each other to learn about one another. If a teacher delays a lesson to build relationships, this can be because they are responding to a need the class is facing. Relationship building lessons requires the approaches Nodding advocates. This section states, "A teacher may delay part of a daily lesson to foster classroom relationships" (NBPTS, 2016, p. 32).

Philosophy of care. A commitment to a philosophy of care appears in four of the FCP and encompasses every aspect of the student, from their behaviors in class to their previous learning, and their life experiences. According to the 
NBPTS, caring for students entails both an understanding of relationships and educational content.

The first example falls under the Section 1.1. This setion discusses a commitment to students by recognizing students' differences. The passage highlights the importance of teachers attending to the messages that students convey through their interactions with others. Specifically, it encourages teachers to watch, observe, and examine students' interactions and behaviors. The NBPTS asserts that such an approach helps students to develop as learners because it requires teachers to consider the student as a source of knowledge about their own needs and achievements. It claims that accomplished teachers are aware of their students, learn from their students, and grow in their teaching practice based on the messages their students communicate rather than imposing pre-conceived ideas onto students. This passage aligns with feminist scholars Hooks (1994) and Musial (2011) who encourage feminist teachers to create environments for the mind, body, and emotional spirit.

The passage reads:

They learn from experience by listening to students, watching them interact with peers, observing them work in different contexts, reading their thoughts and reflections, and otherwise examing their actions and behavior in the learning environment. Teachers also look closely at how students play so they can encourage those students to explore their imagination during instruction. By engaging students on a social, emotional, intellectual, and physical basis, accomplished teachers enhance learning at every age and developmental level. (NBPTS, 2016, p. 14) 
A second philosophical statement about the importance of care appears in Section 1.3 and addresses student equity. This shows the philosophy of care because it requires teachers to be reflective about their teaching practice, to acknowledge their own biases, and not to allow preconceptions to get in the way of meaningful learning for their students. If a teacher is reflecting on their own biases, they are demonstrating care about all the social and cultural circumstances that could impact students' learning. This connects to Hooks (2010) finding that a student's emotional state effects the ability, willingness, and conditions of learning. The passage reads:

Educators recognize their own biases and make certain that any preconceptions based on real or perceived ability differences, exceptionalities, socioeconomic or cultural background, family configuration, sexual orientation, physical characteristics, race, ethnicity, language, religion, age, or gender do not distort their relationships with students. (NBPTS, 2016, p. 15-16)

Section 3.3 further elaborates on the NBPTS' philosophy of care. This proposition is about monitoring students' learning and engagement. In this section, the NBPTS advocates that teachers familiarize themselves with students' past lessons and their learning achievements and uses this to inform their next teaching moves. When they care about students' earlier experiences they have the potential to make the learning experience richer. This connects to Regan \& Brooks (1995) publications that claim feminist teachers have a fondness for the world and the people in it because those that build bridges and spark passion are demonstrating excitement for their students' interests and learning. The passage reads, "Teachers understand that they can build bridges 
between what students know and what they are capable of learning by expanding old interests and sparking new passions" (NBPTS, 2016, p. 27).

Section 4.3 also mentions the philosophy of care. The proposition addresses teachers learning from experience and improving their practice. In this piece the NBPTS focuses on care among teaching colleagues. When they value and show care in each others' work and opinions they create the opportunity to grow together. Because they care about each others' work they provide safe and productive avenues for each other to expand on their practice. This care builds relationships that bind the school community in a culture of growth. This connects to Regan \& Brooks (1995) finding that feminist teachers foster relationships that reflect care and concern for each other. When teachers seek out critical feedback from their colleagues, it build a community of trust because they seek out opportunities where they need to be vulnerable and open to critique in order to grow. This environment allows for colleagues to care for one another throughout the learning process. The passage states, "As savvy students of their own teaching, they know the value of asking colleagues, administrators, and other educators to observe them and offer critiques of their instructional practices" (NBPTS, 2016, p. 32).

Section 5.3 has two examples of the philosophy of care. It discusses teachers collaborating with communities. In this section, the NBPTS affirms again that teachers must care about students' entire well-being if they hope to provide the most enriching learning possible for them. This philosophical statement connects 
to Hobgood's (2012) findings that feminist teachers must provide students opportunities to investigate their own personal identities and draw connections to their own moral agency. Physical, emotional, and social aspects of life are quintessentially personal to each student. When a teacher considers the varied facets of a student's well-being they are also considering personal identity and actions into learning. The first passage states, "The distinctive mission of teaching is the promotion of learning-a complex undertaking in and of itself; but accomplished teachers understand that the physical, emotional, and social wellbeing of students cannot be separated from their intellectual growth" (NBPTS, 2016, p. 39).

In this last excerpt, the FCP call for teachers to take an interest in the challenges their students face daily. The NBPTS says that teachers must consider students' humanity throughout the learning process. It is important that teachers consider how best to share and respond to their emotions throughout their ever changing states. This aligns with Johnson \& Bhatt's (2003) approach to feminist pedagogy where teachers reduce hierarchical classroom dynamics between teachers and students. If teachers are confronting every issue as unique, they aren't using a unilateral top-down approach to teaching. They allow students to see that their emotional reactions to the world around them are worthwhile and they provide students the tools to move forward with their emotional states. In doing this a teacher must show that vulnerability is okay, 
thus eliminating dynamics that could make them authoritarian. Concluding this section, the text states:

Teachers confront the human condition daily in all its splendor and misery what they choose to share, how they respond, and how they prepare students in the face of it all are the factors that distinguish teachers who are truly accomplished. (NBPTS, 2016, p. 39)

Care vs. patriarchy. This section of the analysis has investigated the examples of care found throughout the NBPTS and how those examples align with care as a feminist pedagogical practice and philosophy. Many reoccurring themes presented themselves by emphasizing the importance of fostering positive relationships, listening to students to builds deeper understanding about their lives and how they learn, and instructional practices that connect to their students.

It should be further noted that these practices are not only feminist, but also divergent from patriarchal norms. One example of these norms is from Richardson (2012) who classifies teaching to tests and only teaching knowledge that benefits groups in power as patriarchal pedagogical practices. When discussing care, the NBPTS discounts this teaching practice. The standards advocate for teachers to continuously make decision about instructional practices that take into account students' individual well-being.

The research on patriarchy in the classroom also notes that these points of view block students from many fulfilling opportunities (Mills \& Lingard, 1997). This too is counter to the approaches the NBPTS endorse because care can mean to foster within students a love for the world around them (Regan \& 
Brooks, 1995). The propositions promote this by providing many examples of how teachers should inspire the students to connect with one another and the content. This means teachers are not discouraging students from interacting with certain content of students, but encouraging them to explore their interests.

\section{Diversity}

Diversity is defined as differences based on social categories like gender, race, sexuality, class, and others (Adams, 2013). Appreciation for diversity in the classroom reveals itself in a variety of teaching practices that allow students to see the benefits in human difference (Griffiths, 2006). Teachers redefine difference as strengths, creativity, and power to relate to one another as equals (Gardner, Dean, \& McKaig, 1998). They honor differences among students by creating collective knowledge in the classroom (Gore, 1993; Lee, Ming-yeh, \& Johnson-Bailey, 2004; Mogadime, 2003; Welch, 2006). They also facilitate discussions about student relationships to their own self-identifying groups (Chang, 2002). The teacher is a guide to analyzing students' own community's power structure (Hogood, 2012). This is best achieved when competition is minimized and the teacher builds an environment that allows students to be expressive and embrace diversity (Musial, 2016). They teach students how to embrace their individual diversity and be conscious of how they interact with others (Kishimoto \& Mwangi, 2009; Weiler, K. 1988). The teacher builds relationships among peers to strengthen our democratic society (Kazemek, 1989). 
Practice of diversity. References to a practice of diversity appears in all five propositions. The first example comes from Section 1.1 and discusses teachers commitment to student learning and adjusting their practice based on individual differences. This section refers to teachers planning activities. Specifically, the NBPTS expects teachers to be aware that students have different levels of engagement and understanding in each activity that must each be addressed. This connects with Griffiths (2006) who asserts that feminist teachers avoid standardize teaching practices and instead use a variety of strategies because teachers know they will have to approach instruction differently when students misunderstand. This requires a teacher to be in touch with each student in the class and anticipate challenging and frustrating points in the lesson. At these points they use individualized stratgies to draw the students into learning. The passage states, "The teacher will then look for signs of individual student engagement and address any misunderstandings as they arise" (NBPTS, 2016, p. 13).

The next three examples fall under Section 1.3 and discuss teachers' understanding of student learning. This section encourages teachers to recognize students' individual strengths. According to the NBPTS, there are a variety of ways that teachers can help students to realize their potential. This relates to the feminist research on diversity that encourages teachers to honor differences in the classroom and create a collective construction of knowledge. This could mean that not every students' understanding of a concept is the same. 
They connect to the lessons in different ways. A teacher can nurture these different connections for students by bringing these connections into the classroom learning, giving some students a deeper understanding of knowledge and others a new window in which to think about the content. To accomplish this, teachers must minimize patriarchal constructs that shut out many points of view and instead build on students strengths they bring into the classroom (Gore, 1993; Lee, Ming-yeh, \& Johnson-Bailey, 2004; Mogadime, 2003; Welch, 2006). The relevant passage reads, "Educators determine how to capitalize on those assets as they consider how best to nurture their students' abilities and aptitudes" (14).

The same subsection continues with another example of capitalizing on students' assets. The NBPTS demonstrates that students have a multitude of strengths that can be showcased in a variety of ways. This relates to feminist practices of diversity because providing alternative ways to demonstrate knowledge helps redefine students strengths, creativity, and power which allows for greater opportunities for students to see themselves as equals because they have shared their strengths in learning the new material (Gardner, Dean, \& McKaig, 1989). The text states, "A mathematics instructor may ... provide students with an alternate way to demonstrate their knowledge and improve their abilities" (NBPTS, 2016, p. 15).

As the subsection continues, it addresses how students' circumstances can change. This shows that the NBPTS expects teachers to be attuned to their 
constantly evolving students by ensuring they share their experiences to learn and connect with each other. This aligns with feminist teaching practices where teachers acknowledge, embrace, and encourage diversity among their students because teachers allow students to share what makes them unique and brings that individuality into the lessons (Kishimoto \& Mwangi, 2009; Weiler, K. 1988). The section reads, "Accomplished teachers can develop an array of strategies for sharing differences, identifying similarities, and embracing diversity within the learning environment" (NBPTS, 2016, p. 15).

Section 3.1 examines equity in the classroom. This section explains how teachers should provide students access to resources by cultivating the diverse experiences that students bring with them. Here the NBPTS encourage teachers to allow all students' point of views and acknowledge that students can enrich each other's learning experiences by sharing with one another. This aligns with feminist pedagogy because using individual identies to enrich learning is a way to embrace and encourage diversity and individuality in the classroom (Kishimoto \& Mwangi, 2009; Weiler, 1988). The standard highlights that learning about individual identies strengthen learning for students. The section reads, "Accomplished teachers therefore use everything they know about effective-and ineffective-practices to develop strategies that capitalize on their students' varied backgrounds, using diversity to enrich the learning environment for every student" (NBPTS, 2016, p. 16). 
The fourth subheading in the first proposition is titled, "Teachers Know Their Mission Transcends the Cognitive Development of Their Students." This section begins with highlighting the importance of character development and working through challenges for a successful future. The NBPTS advocates for teachers to teach their students resilience in the face of adversity while also creating a safe environment where students feel comfortable undertaking challenges where they may fail. This aligns with Musial's (2016) feminist practices that endorse minimal competition in the classroom because the fewer win-lose sceneriors a teacher presents the more students affective filters lower and they can take risks and focus on the learning instead of their ranking in the class. When they do experience failure they then have the opportunity to see it as growth in their learning instead of loss of face in a learning situation. The section reads, "To facilitate such growth, educators recognize that failure is a natural part of the learning process; they show students how to cope with it and create environments in which learners are comfortable taking risks" (NBPTS, 2016, p. 16).

The passage continues with an explanation of how students should be advocates for themselves and the community. The NBPTS advocates for students to see themselves as citizens being responsible and accountable for their actions. This aligns with feminist pedagogy that believes being responsible citizens strengthens the democratic process by growing students who are aware of how their actions impact others (Kazemek, 1989). The section states, 
"[Students] develop civic responsibility and digital citizenship, becoming aware of how their actions affect others" (NBPTS, 2016, p. 16).

Under the second proposition there are five examples of an appreciation for diversity. The section addresses teachers knowing their subject matter. The introduction of the second proposition reveals that teachers have a commitment to both student welfare and teaching subject matter. This shows that the NBPTS expects teachers to connect the subjects they teach to broader communities beyond the classroom. This connects to feminist pedagogy because understanding how a subject connects to the broader community can give students the power to better analyze and critique the community's structure (Hobgood, 2012). Providing avenues for students to familiarize themselves to these multiple worlds opens doors for them to think beyond their personal interests and invest in community betterment. It states, "Accomplished teachers are dedicated to acquainting students with the social, cultural, ethical, and physical worlds in which we live, and they use the subjects they teach as an introduction to those realms" (NBPTS, 2016, p. 18).

The Section 2.1 has three instances of an appreciation for diversity. This discusses how teachers organize and link their subject matter to other diciplines. In this section the NBPTS explain how building knowledge occurs. The NBPTS states that there are diverse perspectives in every subject matter and that exposing students to these perspectives helps them better analyze the subject because they understand there are different points of view. This aligns with 
feminist pedagogy because having discussions about diverse perspectives of multiple groups is a key practice (Chang, 2002). Exposing students to these alternative lines of thinking forms a collecive construct of knowledge that feminist teachers try to achieve in their classroom. The passage says, "Knowing that multiple perspectives and interpretations of each content area exist, educators expose students to different modes of critical thinking and show them how to reason analytically about subject matter" (NBPTS, 2016, p. 19).

The substandard continues with explaining how teachers can help students of all levels engage with the content. The NBPTS encourage teachers to use an array of content matter to engage students within a subject. This connects to Musial's (2012) feminist practices because teachers are expected to guide students to more meaningful and expressive understandings. If they use various points of entry for students, then students will have more opportunities for meaningful connections to the subject. It states, "By engaging children and young adults in a broad array of disciplines, educators provide students with appropriate points of entry to appreciate the content" (NBPTS, 2016, p. 19).

This subsection concludes with an example of how teachers can create these different entry points for students. Examples of hopping, and skipping, are used to accomplish a learning goal. This relates to Griffiths (2006) research on feminist practices which encourages teachers to implement a variety of teaching practices in their instruction. The passage states, "Physical education teachers may focus on locomotor movement-such as walking, hopping, or skipping—to 
help students with moderate and profound physical limitations develop gross motor skills and achieve maximum independence" (NBPTS, 2016, p. 19-20).

The last example of appreciating diversity comes in Section 2.2 which discusses teachers specialized knowledge of their subject matters. This section is about balancing student needs, content demands, and teacher wisdom. Here the NBPTS endorses a variety of approaches for presenting new subject matter. This is yet another example of a feminist practice where teachers avoid a onesize-fits-all approach to learning and instead implement a variety of strategies to teach subject matter (Griffiths, 2006). It says, "Accomplished teachers use their knowledge of the most appropriate ways to present subject matter through strategies and techniques such as demonstrations, experiments, analogies and metaphors, interactive learning, and appropriate uses of technology" (NBPTS, 2016, p. 20).

The third proposition has seven examples of appreciation for diversity. The first instance occurs in Section 3.1 which discusses methods for managing student learning. In this passage, the NBPTS promote customized approaches to instruction depending on environment, content, and students. This approach continues to encourage teachers to use a variety of teaching practices and refrain from using one-size-fits-all methods of teaching (Griffiths, 2006). The passage begins by explaining diverse learning styles and continues with:

Accomplished teachers know how and when to alter the organizational structure of their classroom environments to support instructional objectives. They transition among teaching methods, social groupings, and physical layouts to customize their approach, and they develop 
strategies based on learning goals and student needs. For example, depending on instructional objectives, outdoor experiments or classroom simulations may be more productive for students than would a lecture or a discussion. (NBPTS, 2016, p. 25)

The section continues with examples of student grouping and opportunities for learning. The NBPTS advocates for teachers to remain open minded with their lessons. As students explore a topic and concept teachers can modify what they teach next based on students' needs and interests. This aligns with feminist practices where teachers redefine strengths and creativity in students because they remain open to many possibilities in the classroom and cast a wide net of opportunities for their students to learn (Gardner, Dean, \& McKaig, 1989). The text states, "The classroom represents a world of opportunities. One activity can lead to the possibility of many others that will engage students and entice them to explore subjects further, sometimes with their teacher, sometimes with each other, and sometimes alone" (NBPTS, 2016, p. 25).

Section 3.2 has two examples of appreciation for diversity and addresses students learning in group settings. This shows the NBPTS advocates for teacher appreciating diversity because they work with different groups of students and are careful about how they set up proceedures. This connects with Adams (2013) work that indicates feminist teachers work with students from different social categories, race, gender, and other categories because they use management techniques to make sure their communication is constructive and helps students grow. The first sentence of this subsection reads, "Accomplished teachers know how to work with different groups of students. They manage 
those interactions carefully, establishing social norms for constructive communication" (NBPTS, 2016, p. 26).

The second example, under this same substandard, remarks on how classroom norms and how student/teacher relationships are constantly shifting. This is another example of the NBPTS advocating for assessing and adjusting instruction based on the environment and students' situation in the class. This connects to Griffiths (2006) work which advocates for teachers to avoid one-sizefits-all techniques and instead use a variety of teaching practices in their instruction. It states, "To ensure that the learning dynamic remains positive and responsive, educators assess the relative value of classroom structures and organizational requirements when determining which instructional strategies will best enhance student learning in their classrooms" (NBPTS, 2016, p. 26).

Under Section 3.4 there are three examples of the feminist practice of appreciating diversity through regularly assesssing student progress. This example advocates for a variety of teaching practices. Teachers should evaluate the effectiveness of their teaching, assess their students in order to know their current status of understanding, and take into consideration each strategy's effectiveness with individual students. This strategy discounts a one-size-fits-all teaching because they require teachers to reflect, implement changes, and modify instruction based on circumstances and students (Griffiths, 2006). The quote reads, "They assess learning experiences that they create or coordinate with the help of other educators, tracking what students do and do not learn while 
evaluating the effectiveness of their instructional strategies" (NBPTS, 2016, p. 27).

The section continues by providing an expanded explanation of how to approach student assessment. Here the NBPTS clarifies that there is not just one sole purpose for assessing students. Rather, it can serve many functions in the classroom. This aligns with Griffith's (2006) feminist approach where teachers avoid one standardized practice, and use a variety of practices. This evidence states that recording grades is just one example of an assessment practice. Other assessments may serve different purposes that can enrich the student's learning experience and the teacher's instructional methods. The standard says, "Assessment is not always done for the purpose of recording grades; rather, it allows students and teachers to examine their current status" (NBPTS, 2016, p. 27).

The last example in this section addresses how teachers should accommodate students' individual learning needs. When planning a whole group lesson, the NBPTS says that they should consider individual students, allowing for the variety of abilities in the class. This connects with Griffith's (2006) feminsit pedogogical practice to avoid standardized teaching strategies. The evidence suggests that teachers should use a variety of strategies in every lesson which consider both individual and group needs during the lesson. The passage states: "Accomplished teachers find ways to accommodate what they know and learn about themselves and their students within plans for the whole group. They take 
individuals into consideration, thinking across the full spectrum of ability within their classrooms" (NBPTS, 2016, p. 29).

An appreciation for diversity is present again in Section 5.3. This piece of evidence centers on culture, appreciations for linguistics and ethnic influences. This runs parallels to Chang's (2002) work which affirms that teachers who lead discussions about their own diversity as well as other groups. This section explicitly states teachers should discuss the impacts that economic conditions have on political points of views. Uncovering an appreciation for diversity in this case takes the form of appreciating traditions, contributions, and influences. The quote reads:

Teachers also explore the concept of culture within their communities and its influence on children and young adults. Accomplished educators encourage students to appreciate linguistic traditions and ethnic contributions, to study social influences on their expectations and aspirations, and to discuss the effects that economic conditions can have on political views and outlooks. (NBPTS, 2016, p. 39)

Section 5.3 provides one final example of a teacher's appreciation for diversity. This excerpt instructs teachers to pay attention to diversity because it is meaningful to students and can civically engaged student. This promotes honoring differences to build relationship that strengthen a democratic society (Gore, 1993; Kazemek, 1989; Lee, Ming-yeh, \& Johnson-Bailey, 2004; Mogadime, 2003; Welch, 2006). The standards propose that when teachers help students understand similarities and differences in cultures they form civic ideals. These civic ideals and appreciation for multiculturalism are an of honoring difference . The quote states: 
Although careful attention to diversity may challenge teachers, learning about a wealth of cultures can help them work meaningfully with students. An understanding of multiculturalism promotes acknowledgment of differences and similarities which, in turn, inspires students to accept individuals and to adopt civic ideals. Accomplished teachers capitalize on those opportunities so they can respond productively to their students' diverse backgrounds.(NBPTS, 2016, p. 39)

Philosophy of diversity. The pedagogical philosophy of diversity appears in four of the FCP. The NBPTS show a philosophical approach towards diversity because it pushes teachers to understand differences among students. A commitment to diversity first appears in Section 1.1 and discusses teachers commitment to students individual differences. In this case, the section speaks to the importance of considering all students' language abilities and tailoring lessons so that each student can engage and access learning opportunities. This passage intersects with feminist research that encourages teachers to acknowledge and embrace diversity in individual students because the text acknowledges that students language ability does not have to limit their access to content provided that teachers offer a variety of opportunities to access the information (Kishimoto \& Mwangi, 2009; Weilier, 1988). This allows language learners and other students to see themselves as active participants in the classroom community and challenge misconceptions that may perpetuate stereotypes regarding those with limited English language abilities. The passage states the following:

Recognizing that students bring different language practices and proficiencies to the classroom, accomplished teachers also understand the complex role that language plays in learning....teachers empower their 
students by providing them with access points for participating in various situations and occasions" (NBPTS, 2016, p. 13).

Under the same standard and subheading readers once again see a philosophical commitment to diversity. This section of the NBPTS advocates that teachers step outside their own experiences and make thoughtful instructional choices that consider students' background. Teachers must know that students and their communities hold unique outlooks that shape their learning. This section corresponds to feminist pedagogy by considering each student's individual background (Kishimoto \& Mwangi, 2009; Weilier, 1988). It encourages the teacher to go beyond gaining a surface knowledge of their students. When teachers see their students in these complex multidementional ways it can encourage students to see themselves in the same light. The passage states:

What teachers are able to see, hear, and learn about students is influenced by their prior knowledge and experience as professionals. When working with children and young adults who have different backgrounds and experiences from their own, accomplished teachers therefore monitor their impressions and thoughts carefully to acquire a deep understanding of their students and the communities that shape their students' values, outlooks, and attitudes toward learning. (NBPTS, 2016, p. 14)

The philosophy of diversity is expressed again in Section 1.2. This section discusses how students learn and develop. This piece from the NBPTS insists that teachers recognize the diversity within the their students' world and ensure students opportunities within the clasroom to demonstrate knowledge gained from their families and outside community members. This thinking aligns with feminist pedagogy which acknowledges different sources of knowledge including 
non-institutional sources of knowledge (Adams, 2013). Loved ones and those connected to the students outside of school teach our students skills and lessons that may not be relevant to the school's setting. Nonetheless these attributes are valuable to their unique life situations. The document reads, "In a multicultural world, students possess a wide range of abilities and aptitudes that might be valued differently by families, local communities, and schools" (NBPTS, 2016, p. 15).

Another example of a philosophy of the philosophy of diversity comes under seciont 1.3 which addresses equity. In this section, the NBPTS calls for teachers to cultivate awareness of their positionality in the classroom. Teachers must be aware that they have their own unique experiences that differ from those of their students, and should not confuse their experiences for reality or truth itself. The NBPTS calls on teachers to reflect upon the extent to which the teachers own personal biases may distort their understanding of their students' life circumstances and in turn impact how they interact with students. This philosophy requires teachers to take feminist approaches like honoring differences and minimizing patriarchal constructs that may privilege some life experiences over others (Gore, 1993; Lee, Ming-yeh, \& Johnson-Bailey, 2004; Mogadime, 2003; Welch, 2006). A teacher checking their own preconceptions allows students to collectively construct classroom knowledge through a nonbiased relationship with their teacher.

The text states: 
Educators recognize their own biases and make certain that any preconceptions based on real or perceived ability differences, exceptionalities, socioeconomic or cultural background, family configuration, sexual orientation, physical characteristics, race, ethnicity, language, religion, age, or gender do not distort their relationships with students. (NBPTS, 2016, p. 16)

Two more examples of the philosophy of diversity come in the second core proposition. Section 2.2 addresses the specialized knowledge needed to be a teacher. This section speaks to the importance of connecting with students' stages of development and maturity, which may differ from that of their immediate peers. When they see their students at different places grappling with the content, they adjust their approach to reach a desirable pace for the class. This connects with Musial's (2016) feminist research that asserts teachers should minimize competition in the classroom. Competition can lead students to believe that one group holds more power than another. In reality, students with different developmental and maturity levels can all exercise strengths and power when given the proper outlets. The passage says, "Balancing the insights of pedagogical and subject matter expertise helps teachers evaluate and resolve daily issues-decisions that include which aspects of subject matter to emphasize and how to pace instruction" (NBPTS, 2016, p. 20).

A passage under a different subheading that addresses multiple paths to knowledge in the same proposition speaks to another aspect of the philosophy of diversity. In this section, the NBPTS calls for teachers to employ diverse strategies when engaging with students. Doing so, allows students to have a deep understanding of content so that it can be tailored, modified, and adjusted 
to satify the demands of all learners. Diverse teaching strategies ensures different platforms for students to understand the content and apply what they have learned in a myriad of ways. This coincides with Griffiths (2006) who says that feminist teachers avoid standardized teaching practices and instead use a variety of methods for students to access knowledge. When teachers develop a deep matrix of understanding they show students the power of differences in perspectives. The passage reads:

Thus, in the eyes of accomplished teachers, the acquisition of knowledge does not signify a lower form of understanding. Rather, it represents a distinctly intellectual undertaking - a rich, demanding, creative process calling on the strategic coordination of skills, abilities, and dispositions to develop a deeper, more discerning matrix of understanding. (NBPTS, 2016, p. 22)

The next section underscores the importance of lifelong learning. This section advocates that teachers respect and celebrate humanity's diversity. To achieve this standard requires teachers to know about cultures and backgrounds other than their own and to use that knowledge to impact students in a positive manner. Feminist pedagogy advocates for honoring differences like those described above. In doing so, patriarchal constructs are minimized because students are encouraged to hold values that allow them to collectively share and create knowledge (Gore, 1993; Lee, Ming-yeh, \& Johnson-Bailey, 2004; Mogadime, 2003; Welch, 2006). The passage reads, "Such teachers embody the virtues they impart to their students: curiosity and a love of learning, tolerance and open-mindedness, fairness and justice, an appreciation for our cultural and 
intellectual heritages, and respect for human diversity and dignity" (NBPTS, 2016, p. 33).

The section goes on to explain the importance of providing students with multiple diverse perspectives of a topic or content area. This section corresponds with feminist pedagogical practices which consider multiple perspectives to be a hallmark of a strong democratic society. It recognizes the varied ways in which students can acquire the knowledge they draw on to grapple with the world's problems (Kazemek, 1989). When students consider multiple perspective they are open to relationships that allows for problem solving necessary for society to push forward. This section concludes with the quote, "Moreover, they epitomize the intellectual capacities they foster: the ability to reason carefully, consider multiple perspectives, question received wisdom, adopt an inquiry-based approach, solve problems, and persevere" (NBPTS, 2016, p. 33).

Another instance of the philosophy of diversity comes in Section 5.2, which discusses teachers collaborating with families. In this section, the NBPTS calls for teachers to learn about their students' family experiences, and how those experiences connect to their culture and values. This is relevant because each student will have diverse family contexts to draw from. Building relationships with students' families and learning about their culture and beliefs is significant in feminist teaching practices as well, because it honors the differences among students (Gore, 1993; Lee, Ming-yeh, \& Johnson-Bailey, 2004; Mogadime, 2003; 
Welch, 2006). The standard states, "Understanding that some families may take more time than others to gain confidence in school-home relationships, teachers proceed patiently, learning about cultures, beliefs, and priorities while expressing respect for families and demonstrating their attention to students" (NBPTS, 2016, p. 38).

Diversity vs. patriarchy. This section of the analysis has investigated the examples of diversity throughout the FCP and how this evidence connects with an appreciation of diversity as a feminist pedagogical practice and philosophy. Various patterns presented themselves through highlighting the significance of using a variety of instruction strategies, learning about many cultural experiences and perspectives, and structuring the class so that all students can access the content in meaningful ways.

While these practices are highlighted as feminist, it should also be noted that they are incompatible with patriarchal norms. One example of these norms is that teachers grant certain institutional opportunities to groups in power (Messner, 1997). When discussing diversity, the FCP disapproves of this sort of favoritism repeatedly throughout the text. Instead, the standards instead call for teachers to have individual and cultural awareness when interacting with students, facilitating student-to-student interactions, and planning lessons. Patriarchal approaches also drive out multiple approaches to teaching that offer students a variety of learning experiences. Instead, it uses a one-size-fits-all approach to instruction (Griffiths, 2006). This conflicts with the FCP because 
they espouse pedagogical practices that enrich learning through allowing students to see the world through multiple perspectives and experience learning by working with many people. Using a variety of instructional approaches and exposing students to multiple understandings of knowledge is a repeated consistently throughout the text.

\section{Collaboration}

Finally, collaboration is defined as, the ability to work with a group, offering support to each other, and creating a synergistic environment for everyone (Regan \& Brooks, 1995). This surfaces in student-to-student learning and where the teacher reflects and builds on these practices (Gardner, Dean, \& McKaig, 1989; Kazemek, 1989; Regan \& Brooks, 1995; Sykes, 1996; Thurber \& Zimmerman, 2002; Watson, 2008). The teacher facilitates the learning so that students can interact cooperatively (Kazemek, 1989). This includes the teacher showing students how to use knowledge to empower each other, and not overpower their peers by focusing on the collective responsibility of a group (Gardner, Dean, \& McKaig, 1989). Strategies like giving students a space to speak without interruption by peers while also and calling on each other to hear opinions are examples of collaborative practices (Watson, 2008). These teachers teach their students to use their voice to build relationships and empower each other to shift the culture (Thurber \& Zimmermen, 2002). Collaborative teachers also bring their colleagues together to empower the school community (Regan \& Brooks, 1995). Inclusiveness and shared ownership 
is essential. These teachers see themselves as part of a web connecting people, ideas, and communities together (Helgesen, 1990).

Practice of collaboration. Evidence connecting to the teaching practice of collaboration appears in three of the five propositions. The Second Core Proposition contains one of these examples in Section 2.3. This standard espouses that teachers should help students see multiple pathways to knowledge. This evidence echoes ideals that teachers should provide students with outlets to share their own knowledge with other students thus modeling a practice of collaboration (Gardner, Dean, \& McKaig, 1989). The standard proposes that teachers model processes that examine others' findings. Examining others answers to problems similar to those the student is currently facing is a method students can use to share knowledge with one another. The passage reads, "Accomplished educators model those processes for students, showing them how to pose problems and work through alternative solutions, as well as how to examine the answers that others have found to similar problems" (NBPTS, 2016, p. 21).

The Third Core Proposition has seven examples of the practice of collaboration, half of which appear in Section 3.1. The key part of the text calls for teachers to use multiple methods of instruction to meet their teaching goals and leads with recommendations of how students should work together. This connects with Kazemek (1989), who favors students interacting with one another in cooperative ways because the standard suggests group learning and 
classroom discourse that is cooperative and mediated by the teacher.

Cooperative group learning is an key aspect of collaborative practices. According to the FCP, teachers can promote group learning through specific classroom activities including mediated discussions: "Accomplished teachers possess a range of pedagogical skills-for instance, they facilitate student inquiry, advise cooperative learning groups, and mediate classroom discourse" (NBPTS, 2016, p. 25).

Section 3.1 further advocates the practice of collaboration. This gives teachers direction on how to facilitate classroom discussions. This echoes Watson's (2008) position that teachers should allow students to have a speaking space free from interruption, allowing all voices to be heard. The standard proposes round table discussions that promote students finding their own answers to thoughtful questions which spark thoughtful discussion. In order to create such a harmonious environment, a teacher would need to facilitate a speaking space void of interference where all students are allowed express themselves. The passage reads:

Thus, accomplished teachers understand what they and their students can reasonably achieve in a roundtable discussion, when they should hold back and allow students to determine their own solutions, and which questions they can pose to provoke the most thoughtful classroom conversation. Importantly, effective educators possess a comprehensive knowledge of instructional methods, broad and deep in scope. (NBPTS, 2016, p. 25)

Section 3.1 also exhibts a commitment to collaborative practices. Here the proposition advocates for a wide range of expertise as students learn a topic. 
This section models many collaborative themes in feminist pedagogy such as facilitating student-to-student learning, working in groups, offering support to each other, and asking colleagues for help (Gardner, Dean, \& McKaig, 1989; Kazemek, 1989; Regan \& Brooks, 1995; Sykes, 1996; Thurber \& Zimmerman, 2002; Watson, 2008). Some examples of how these feminist strategies can be executed, involve inviting stakeholders and colleagues to share expertise with the students as well as mobilizing peer tutors. It is considered a collaborative act to seek support and help from groups such as peers, students, other teachers, paraprofessionals, community members. The standard states:

To inspire students further, teachers invite stakeholders and colleagues to the classroom so they can share their experience and communicate their expertise on specific topics. Accomplished educators appreciate how the knowledge and skills of other individuals can complement their own talents and enhance their students' understanding. They know the value of mobilizing students as peer tutors for the same reason. Accomplished educators thus enlist a wide range of support-from students, teachers, and paraprofessionals to family and community members - to provide their students with instructional opportunities that will augment their learning. (NBPTS, 2016, p. 25-26)

Another reference to collaborative practices appears in Section 3.2. Here, the FCP gives an explanation of how student learning should have varied groups and settings. This particular excerpt calls for students to take responsibility for their classmates learning and aligns with feminist pedagogy that grants importance to collective responsibility in the classroom (Gardner, Dean, \& McKaig, 1989). The standard proposes that through constructive communication and productive roles, students can be responsible not only for their learning but also their group- 
mates learning. Collective responsibility takes form in these specific student roles that guide the learnings of all students in the group. The passage reads:

Accomplished teachers know how to work with different groups of students. They manage those interactions carefully, establishing social norms for constructive communication. helping students adopt productive roles vis-à-vis their teachers and their peers, and showing students how to assume responsibility for their learning and for that of their classmates. (NBPTS, 2016, p. 26)

This section concludes with another practical approach to student collaboration. The standard is consistant with ensuring that student collaboration is present in the NBPTS accomplished teaching practices. Facilitating studentto-student learning is a feminist collaborative teaching strategy that reveals itself in this instance through teacher guidance and support with group, pair, and oneon-one adult lead learning (Gardner, Dean, \& McKaig, 1989; Kazemek, 1989; Regan \& Brooks, 1995; Sykes, 1996; Thurber \& Zimmerman, 2002; Watson, 2008). The text says, "The environments that teachers create guide student behavior and support learning as it takes place in large or small groups, in pairs, independently, or one-on-one with the teacher or another adult" (NBPTS, 2016, p. 26).

Proposition 3.5 has two more examples of collaborative teaching practices. This standard calls for teachers to engage students in their own learning process. This is in agreement with Kazemek (1989) who say feminist practitioners nurture a sense of responsibility and cooperation with one another. The standard advises teachers to work collaboratively with their students to write objectives and plan lessons. Having students take on this active role in the planning of their 
classes grants them the responsibility to be accountable for both their and their peers' learning. The particular standard references collaboration expressly: "Throughout the learning process, accomplished teachers work collaboratively with their students. They plan their instruction carefully-identifying educational objectives, developing them, and discussing them with students" (NBPTS, 2016, p. 29).

The Fifth Core Proposition has ten examples of collaborative teaching practices. This proposition concentrates on teachers as members of their own learning communities. Thus, they not only set up spaces for students to collaborate, but they also collaborate with their peers to ensure quality teaching practices. The introduction to this proposition directs teachers to reach out to other communities and form partnerships to enhance their own learning. This approach aligns with Thurber \& Zimmerman (2002) who applaud feminist teachers for building friendships where they exchange instructional ideas to impact the school community. Going beyond the classroom and connecting with both local and global groups, collaborating with other professionals, and partnering with families are all examples of friendships that benefit students and the school. The introduction states:

They connect with local, state, national, and global groups in person of via technology to take advantage or a broad range of professional knowledge and expertise. Accomplished educators draw on those resources when instructing their students and participating in duties that contribute significantly to the quality of schools and student learning. Those duties address two areas of responsibility: collaboration with other professionals to improve the effectiveness of schools, and partnership with families and 
other stakeholders to promote the education of children and young adults. (NBPTS, 2016, p. 35)

Section 5.1 advises on how teachers should collaborate with other professionals to improve school. This section has eight examples of collaboration as a professional practice. This specific piece of evidence contains messages about teachers having proactive roles in the school community that contribute to professional development, participate in policy making, and developing productive learning communities. This section reflects Regan, \& Brooks (1995) who argue that feminist practice can build self-efficacy and empower the school community. When teachers both contribute to their peers' professional development and engage with policy decisions they are leading the school community and empowering others with knowledge and protocol that can benefit the school community. The passage reads:

The National Board advocates proactive and creative roles for teachers. Those functions involve analyzing and constructing curricula, coordinating instruction, contributing to the professional development of staff, and participating in other policy decisions fundamental to the development of highly productive learning communities. (NBPTS, 2016, p. 35)

Section 5.1 follows with more practical approaches to collaboration. In this instance, the text discloses a need for teachers to actively collaborate in order to reflect upon and change curriculum and policies while also communicating with stakeholders these these changes. This echos Thurber and Zimmerman's (2002) work which endorses teachers exchanging instructional ideas to inform pedagogy and make significant impact on their school community because teachers are both working collaboratively and communiticating that collaborative 
work to the stakeholders. The standard states teachers should collaborate which is an exchange of ideas. Additionally, they should communicate with others in the school community which is an essential piece to ensuring lasting impacts at the school. The proposition states:

Accomplished teachers thereby take the initiative to analyze curricula critically, identify new priorities, and communicate necessary changes to the school community. To perform that work effectively, teachers must have a thorough knowledge of their students and curricula as well as a willingness to question conventions and work collaboratively with educational stakeholders. (NBPTS, 2016, p. 36)

Section 5.1 continues with more examples of teachers embarking in collaborative practice. The text provides details relating to collective ownership by planning curriculum programs, setting academic tracks, and refining systems. This resonates with Helgesen's (1990) work that asserts that shared ownership is part of effective collaboration. The NBPTS urge teachers to work with other educators to plan instructional programs. They also encourage teachers to work with administrators to navigate and improve systems. The NBPTS finishes with a call to participate with teams and departments for effective decision making for the school community. All these recommendations require the collaborative practice of shared ownership with others to be implemented in the manner the proposition suggests. The passage reads:

Teachers work closely with administrators and staff to navigate systems, structures, and schedules so they can implement improvements that modify organizational and curricular aspects of instruction cohesively. Accomplished teachers understand the technical requirements of a wellcoordinated curriculum, possess the interpersonal skills needed to work in groups, and exhibit a readiness to join their efforts in the interest of school communities. Those qualities enable educators to participate effectively in 
planning and decision making in teams, departments, and other educational units outside the classroom, laboratory, or studio. (NBPTS, 2016, p. 36)

The following paragraph in 5.1 extends these recommendations even further. The standard reaches beyond mainstream curriculum and programs and focuses on unique groups of students like those who speak multiple languages or are in special education programs. This evidence could be sorted into the appreciation for diversity portion of this project, however it was placed here because its focus is mainly on collaborative practices. This passage is much like Helgesen's (1990) point of view that feminist teachers do not see themselves in a top-down hierarchy, but instead a web reaching out and supporting others simultaneously. This portion of the text builds on the previous paragraphs themes of working together. Here, teachers unite with other educators and form partnerships to ensure inclusive educations. The teachers foster cooperation with counselors and those who offer other programs for specialized populations. They work in tandem to provide the proper attention to students' needs. Working in tandem, fostering cooperation, and uniting educators are all terms that suggest equitable balance of power and strengths, like webs are structured. The text states:

Accomplished educators foster cooperation among teachers and counselors of English learners, and others who offer high-quality programs featuring English as a new language, bilingual education, and English immersion. Importantly, they uphold the requirements of compensatory education with a similar sense of vigilance and dedication. Accomplished teachers are adept at working in tandem with other educators to provide students with the attention they need. (NBPTS, 2016, p. 36) 
5.1 maintains with the central theme of teachers practicing collaboration. The next paragraph relays the topic of improved and strengthened practice. This same theme is reflected in the feminist literature which calls for teachers to reflect and building on their practices while also encouraging peer efficacy and empowerment (Gardner, Dean, \& McKaig, 1989; Kazemek, 1989; Regan \& Brooks, 1995; Sykes, 1996; Thurber \& Zimmerman, 2002; Watson, 2008). Teachers build their practice by working with one another to strengthen practices. Teachers find peer efficacy through observing one another or collaborating to improve teaching methods and pursue excellence in concert with their peers. The proposition reads:

They observe colleagues in the classroom, engage in pedagogical discussions, and collaborate to improve their teaching methods and explore new instructional strategies. Accomplished instructors may focus on different aspects of their practice, based on opportunity, need, and disposition; however, they share a common commitment to pursuing teaching excellence in concert with their peers. (NBPTS, 2016, p. 37)

5.1 goes on to address how teachers should address problems that arise at schools. The NBPTS recommends teachers resolve problems with their colleagues and build systems and networks that foster innovation. This approach to teaching relates to Regan \& Brook's (1995) notion that feminist teachers bring colleagues together. The standards recommended teachers help their colleagues identify and resolve problems and develop networks that will help their school prosper as both of these actions brings people in the school together. The passage reads: 
Accomplished teachers in those schools help their colleagues identify and resolve problems while encouraging them to experiment with different teaching methods and forms of instructional organization. They work as teacher leaders, strengthening professional development and advocating improvements. Educators in less successful schools strive to promote the same traits of excellence-to build systems, develop networks, and foster a culture of innovation that will help their schools prosper. (NBPTS, 2016, p. 37)

Section 5.1 concludes with examples of how the NBPTS imagine teachers to work with the broader community to better the school system. This standard cites mentorship, teamwork, and serving on councils as examples that fit into collaborative practice. This corresponds with Thurber \& Zimmerman's (2002) position that teachers should use their voice to build relationships and create change. The text recommends teachers become mentors to novice teachers, serve on district policy councils, and work alongside their administrators to assume responsibility for quality school programs in order to accomplish these things successfully a teacher would need to build strong relationships with all of these parties. The text states:

They may mentor novices, form study groups, demonstrate new methodologies, serve on school and district policy councils, or engage in scholarly inquiry and artistic expression. Teachers work with their colleagues as members of a team, sharing their knowledge and skills while contributing to the ongoing development of strong schools. Alongside their administrators and other school leaders, they assume responsibility for the quality of their schools' instructional programs. (NBPTS, 2016, p. 37)

The final example in the Fifth Core Proposition falls in Section 5.2. This portion of the text urges teachers to work collaboratively with families. This connects to Helgesen's (1990) study of feminist pedagogy which promotes 
creating a web of networks that reach out to one another. The text of the NBPTS suggests teachers work creatively with families, inform caregivers, and understanding their students' homes. To accomplish this, teachers are committed to seeing themselves as partners with the family unit, thus acting like a web which supports students and families through the child's education. The passage states:

Accomplished teachers must possess a thorough knowledge of their students as individuals to work creatively and effectively with family members. Advancing the intellectual development of students is a teacher's foremost responsibility, but accomplished teachers understand that a broad range of student needs can influence that goal, such as the need for informed caregivers to provide guidance and support. By learning the dynamics within their students' homes, teachers appreciate how they can work with families to address student needs and advance educational gains. (NBPTS, 2016, p. 38)

Philosophy of collaboration. The philosophy of collaboration appears in two of the FCP. The forth core proposition contains the first example in the introduction of the standard. This section discusses teachers' systematic practices. It refers to teachers who use others' suggestions as models for their own teachings. This section of the NBPTS demonstrates a commitment to collaboration by arguing that teachers must rely on others' knowledge in order to grow in their craft. The craft in this case is bigger than any one individual because growing relies on new ideas and methods developed by others. Recognizing complexities and commitment to continual learning connects with feminist pedagogical practices that encourage teachers to reflect and build on their teaching practices (Gardner, Dean, \& McKaig, 1989; Kazemek, 1989; 
Regan \& Brooks, 1995; Sykes, 1996; Thurber \& Zimmerman, 2002; Watson, 2008). The passage reads:

Accomplished teachers are ready to incorrperate ideas and methods developed by other educators to support their instructional goals-namely, the advacement of student learning and the improvement of their practice. What exemplifies excellence, then, is a reverence for the craft, a recognition of its complexities, and a commitment to lifelong learning and reflection" (NBPTS, 2016, p. 31).

Another example of the philosophy of collaboration comes under Section 4.2. and discusses teacher feedback an its use in positively impacting student learning. This section promotes teachers cultivating their own learning by consulting with others. The NBPTS asserts that working with others is an essential part of developing as a teacher. Good teachers see their colleagues as experts that can support them in growing their craft. This section connects with feminist practices because asking others in the profession for feedback is a way of recognizing others as trusted sources of support and friendship. When teachers confide in others to grow as professionals, they demonstrate a confidence that their colleague will give them feedback that will aid in developing their practice (Thurber \& Zimmerman, 2002). The relevant passage reads, "As savvy students of their own teaching, they know the value of asking colleagues, administrators, and other educators to observe them and offer critiques of their instructional practices" (NBPTS, 2016, p. 32).

Under Section 4.2 the NBPTS discusses how teachers think in systems to positively impact students. This example encourages teachers to use collaborative approaches in their teaching and expects teachers to test out 
approaches through trial and error. Doing so allows teachers to refine and share what they have learned with others. This aligns with the feminist pedogogical appraoch that encourages teachers to come together when teaching (Regan \& Brooks, 1995). The passage states, "Because testing new approaches and hypotheses is a commonplace habit among such teachers, they might conduct, publish, and present their own research, if so inclined" (NBPTS, 2016, p. 32).

Two additional examples of the philosophy of collaboration appear in Proposition Five. Section 5.1 talks about teachers working collaboratively with families. This section shows that the NBPTS champions collaborating with students' families as a way of growing students' opportunities for learning. Showing families which programs can best support their child can give students a leg-up in learning throughout the rest of their life. This connects to the feminist idea that we, as a society, are a network of webs because teachers see their classroom as such; however classrooms are not the only place learning can occur. Teachers rely on other programs to guide students' learning (Helgesen, 1990). The relevant passage reads: "Teachers encourage families to become active participants in their children's education by acquainting them with school programs and enlisting their help to develop skill sets and foster lifelong learning" (NBPTS, 2016, p. 38).

Section 5.3 addresses teachers working with the broader community. This statement rejects any notion that one person holds all the knowledge and expertise in a classroom or schools. It embraces the idea that everyone is part of 
a larger community of learners growing together to help other learners grow together. This too embraces the feminist idea that teaching, to be done effectively, requires a web of people and support (Helgesen, 1990). The section concludes with the evidence of the philosophy of collaboration. The text simply states, "Accomplished teachers need not teach alone" (NBPTS, 2016, p. 39).

Collaboration vs. patriarchy. This final analysis has uncovered the examples of collaboration within the NBPTS and how these examples espouse feminist pedagogical practice and philosophy. Many examples of collaboration are revealed throughout the FCP. Some of these examples focus on students collaborating with students, teachers collaborating with students and staff, and teachers working with outside community organizations. These examples run throughout the text and reveal the NBPTS commitment to the feminist practice of collaboration with multiple relationships.

This is contrary to patriarchal approaches where teachers see themselves as the leader in their classroom (Richardson, 2012). This attitude towards teaching is in complete opposition to the FCP. The text illustrates several instances where teachers work with others to accomplish goals. Connecting with school counselors, administrators, families, and outside community organizations to provide better services and education to students are all practices of accomplished teachers throughout the text.

Those hypermasuline teachers also demand ultimate control over their classroom and reject professional development because they believe they hold 
the expert knowledge in their classrooms (Richardson, 2012). These behaviors are rejected by the FCP. The NBPTS continuously suggest different ways teachers can engage with others to develop as professionals. As they work with others they are expected to reflect upon their practice, grow in their instructions, and provide better education to their students. The NBPTS says this is done through accessing other people's talents and using them for the benefit of the class.

\section{Closing}

The booklet "What Teacher should Know and Be Able to Do" is painted with examples of care, diversity, and collaboration. All of which represent feminist appraoches to classroom philosphy and practice. Every proposition and subsection within the booklet carries examples of these feminist traits. Furthermore, there are no endorsements of any partiarical practices throughout the entire text, but there are many examples of text that refute patriaricahl practices all together. After examining each sentence of the FCP it is clear that the NBPT embrases feminist teaching practices.

These findings uncover a pressing issue that educators and those in the system have endured for far too long. The education system has created a dynamic where the public policies directly contridict the national standards. This discrepancy leaves educators in tight corners where they have to choose between meeting the standard of an exemplar teacher or following the law. Placing teachers in a situation with patriarchal rules and feminst expectations 
that require them to either comprimise their ethics by following the rules or meeting the expectations.

This project set out to show that the current effort to recruit more male teachers is misguided and counterproductive. When recruitment is part of a broader effort to ensure greater diversity in the classroom, the goal is laudable. However, this is not consistently the reason districts are recruiting men. While wanting more males in the teaching profession for reasons of diversity is a notable feminist ideal, many endorse male recruitment into the profession with the hopes that it will result in more patriarchal practices in the classroom. Stricter discipline policies or a perpetuation of the notion that males are simply better teachers than females often emerge in this discourse. The goal of this project was to shift the focus of educational discourse away from teachers' gender and look towards their teachers' teaching abilities as compared to the professional standards laid out in the NBPTS.

Though it may not have been the intent of the authors of the NBPTS to incorporate feminist pedagogical principles into their text, the document nevertheless reflects these principles. Examples of care, appreciation for diversity, and collaboration as defined in feminist literature are sewn into every proposition, substandard, and page of the document. While the document is full of feminist values, it is also significant that there is a complete absence of any mention of a teachers' gender or patriarchal practices. This illustrates a key disconnect between the common discourse and policy making in education and 
the standards for professionalism in the field. Public discourse and policy have made teachers' gender identity a factor in education while professional standards do not. As a result, teachers receive mixed messages about their job duties and classroom expectations, which creates a double standard for educators. 


\section{Chapter 5 Discussion}

As clearly stated in the title, the NBPTS focus on what all teachers should know and be able to do regardless of their gender. The booklet continuously expounds on the philosophical beliefs that a teacher should hold, in addition to the practices they should perform. It emphasizes teachers' commitment to both their students and subjects and underscores their responsibility to both managing and monitoring student learning. The document closes by encouraging teachers to understand and change the systems they work in and work with the community to accomplish these goals.

After thoroughly examining the NBPTS to determine the national expectations for teachers, it is clear that feminist pedagogical approaches are the national standard for classroom teaching practices. It is also clear that patriarchal practices are not endorsed or lacking as being effective approaches to pedagogy. However, in our present day system we continue to see education policies that embrace patriarchal approaches. Shifting these policies so that they better align with professional standards is key to ensuring that our teachers can incorporate these standards with the highest fidelity into their practice. This concluding chapter examines current education policies in the United States that resonate with patriarchal or hypermasculine practices. It takes a closer look at the media's discourse regarding these issues and makes recommendations on how these practices could be reformed to fit both feminist strategies and align with the NBPTS. 


\section{Teachers Carrying Guns}

In February of 2018 the 45th president of the United States of America voiced his support for arming teachers across America with guns. This was in response to a school massacre where a teen killed seventeen high school students during the school day. Teachers carrying guns to school is a hypermasculine policy because it gives virtue to violence (Mosher $\&$ Tomkins, 1988). This policy suggests that the best way to protect our students from violence is through the threat of violence. The NBPTS does not commend any acts or threats for violence from teachers.

The fifth proposition instructs teachers to work with community members to improve schools. When the school community feels threatened by violence, instead of teachers carrying a weapon to intimidate an attacker they can work with the entire community to alleviate the possibility of danger on campus. These collaborations can take place with administrations, school boards, local law enforcement, teachers unions, counselors, parents, students, and possibly other stakeholders. These groups can bring their expertise and concerns together to research the best methods of protecting their school community. There are many safety measures schools can take that do not require teachers to carry guns or threaten violence at school. This requires a nation-wide effort of teachers collaborating with their local, state, and national communities to change current laws and policies. These collaborative solutions have the potential to 
make the community feel safer without a teacher needing to carry a firearm while teaching.

\section{National Discipline Policies}

During Obama's term in office a "Dear Colleague Letter on the Nondiscriminatory Administration of School Discipline" was published by the U.S. Department of Education Office for Civil Rights. The purpose of the letter was to issue guidance to assist public schools in meeting their obligation under Federal law to administer school discipline without discrimination. (U.S. Department of Education, 2014) This action was an effort to address the school to prison pipeline in America, a phenomenon where disadvantaged students get funneled into the criminal justice system through misbehavior at school. The letter calls for equitable discipline for students, no matter their race and requires school discipline to be handled by school administration, not campus law enforcement (Goldberg, 2018). This policy aligns with both feminist pedagogy and the NBPTS. The first proposition has a subsection titled "Teachers Treat Students Equitably," which demonstrates an appreciation for diversity by calling teachers to recognize their bias towards students' background (NBPTS, 2016, p.16).

However, in March 2018, it was reported that this policy is now under consideration to be rolled back by the federal government. A 60 Minutes piece with The Secretary of Education, Betsy DeVos, revealed she would like to end this policy, which guides schools on how to identify and avoid

discrimination. The New York Times reported that though there is no evidence to 
support the assertion, Florida State Senator, Marco Rubio believes this policy lead to systemic failures that contributed to the high school shooting in Parkland, Florida (Goldberg, 2018; Stahl, 2018). Removing this policy would mean that schools could implement discipline from law enforcement, as well as discriminatory practices that apply harsher punishments for the same behavior on students of color than their white peers. This approach illustrates Messner's (1997) point that patriarchal thinking grants certain privileges, which in this case is softer punishments for the same behavior, to groups in power.

\section{Zero-Tolerance Policy}

During the mid-90's zero tolerance policies started emerging in schools. These policies allowed no second chances for students who brought weapons or drugs on campus or threatened the school any in other way. With these policies, schools saw a surge of metal detectors, surveillance cameras, and police officers patrolling campuses disciplining students. These policies use punishment as deterrent, leading schools to have increased numbers of suspensions and expulsions, with a disproportionate number of these policies impacting male students of color (Sanchez, 2018). Thus, zero-tolerance became another patriarchal practice in schools that granted certain privileges to groups in power, while cornering others into enduring harsher consequences (Messner, 1997).

Money has been invested in technology and practices that are commonly found in the criminal justice system. Yet, school mental health services have not 
been prioritized alongside the implementation of the zero-tolerance policies. This prevents schools from effectively identifying and serving deeply troubled students (Sanchez, 2018). If we turn to the NBPTS, we find guidance on how to address this issue through aspects of care. The third proposition encourages teachers to make efforts to build positive relationships, maintain structure in the classroom, and ensure student safety (NBPTS, 2016, p. 24). This environment promotes learning, rather than using discipline to prevent negative behavior. Proposition Five also endorses collaboration among colleagues and families to help ensure effective schools (NBPTS, 2016, p. 35). The negative impacts of zero-tolerance policies could be alleviated through adequate counseling staff and opportunities for collaboration with this staff and families to better serve the student. This effort has lead to teachers building trustworthy relationships with students and influnced practices that positively impact the school community (Thurber \& Zimmerman, 2002).

\section{Standardized Testing}

In the world of academia, standardized tests have been compared to the system of apartheid (Nichols \& Berliner, 2008). This is due to largely to standardized tests ability to better measure socio-economic status rather than students' knowledge of content or skills (Kohn, 2000). Since the introduction of high stakes standardized tests in the early 2000's, the U.S.'s weakest students have been pushed out or allowed to drop-out of schools so that school districts can reap the benefits or having higher test scores (Nichols \& Berliner 
2008). This system has put the focus in education more on competition and less on learning. Teachers with patriarchal beliefs often solely prepare students for these tests believing there is merit in competitive forms of assessment, even though the tests often measure students' superficial thinking skills (Kohn, 2000 \& Richardson, 2012).

Many times these tests were not initially designed to measure classroom teaching or student's content knowledge (Kohn, 2000). Using a standardized test to measure students' learning is not recommended or suggested in the NBPTS. However, feminist approaches that do not rely on competitive measures to assessment are recommended in the document. The third proposition provides guidance on regularly assessing student progress. Standardized tests cannot function as a regular assessment of students since they are usually given on a yearly basis. The NBPTS state that assessment does not always need a grade or rank, which can be competitive. Instead, it should be used as a checkin to see where the lesson is headed or for students to self-assess and take responsibility for their own learning. Teachers are encouraged to monitor students so that they can provide constructive feedback that allows them to grow (NBPTS, 2016, p. 27-28). These are some of the ways to avoid competitive teaching practices that are common with standardized testing (Griffith, 2006).

\section{Teacher Evaluation and Merit Pay}

During the Obama administration the Race to the Top initiative was developed. This initiative offered states money if they tied students' standardized 
test scores to teacher evaluation and merit pay. Most states adopted a valueadded measurement to their teacher evaluation system. The idea behind this policy was that better teachers are defined by their students' better tests scores and thereby are rewarded by getting paid more. Their colleagues will see that they get paid more and will be incentivized to work harder to better themselves and their student test scores (Berliner \& Glass, 2014). This policy once again introduced a patriarchal mindset that encouraged drill-and-kill teaching methods, and closed off collaborative practices amongst colleagues (Berliner \& Glass, 2014 \& Richardson, 2012). The policy actively discouraged collaboration because those teachers whose students did receive higher test scores did not want to share their teaching strategies, in fear that other teachers would use them, gain higher test scores, and take the bonuses (Smith, 2012).

This also set up a system where teachers no longer wanted to teach students with unique circumstances like English learners or those in special education programs. This policy is in direct conflict with the NBPTS and feminist teaching practices. The first proposition advocates for teachers to recognize students' individual differences and adjust instruction accordingly (NBPTS, 2016, p.13). This leaves no room for repetitive teaching methods generally associated preparing students for standardized tests. The merit pay policy also blocks many of the collaborative practices to improve schools found in the fifth proposition (NBPTS, 2016). With the merit pay policy teachers are incentivized to prepare their students for a narrow task and hope that other students in the school do not 
perform as well. Removing merit pay from teacher evaluation systems would allow teachers to embrace the diversity of their students, use a variety of teaching practice, and collaborate with colleagues to improve the entire school setting.

\section{Teach for America}

Teach for America (TFA) is an organization that recruits newly graduated college students who aspire to enter into fields like business, to commit to two years of teaching in a low socioeconomic communities. TFA teachers are provided an intensive summer teaching course and weekly planning sessions with their peers (Berliner \& Glass, 2014). While the TFA teachers may individually practice feminist pedagogy that aligns with the NBPTS, the organization and policy behind its development reflects a patriarchal mindset. This program was founded on the premise of vilifying teachers currently in the classroom, claiming that they were "bad" while suggesting that our students need newly graduated college students with little to no experience in education to save them from these "bad" teachers. This assumption is problematic because it assumes that first and second year teachers are better than classroom teachers with more experience and education. This program structure aligns with patriarchal approaches that lead teachers to believe they are the only leading authorities on teaching and therefore can refuse to collaborate with their peers (Richardson, 2012). 
TFA gives credence to the notion that intelligent young newcomers are better teachers than older, more experienced teachers. This notion obstructs and limits potential opportunities for collaboration among peers and runs in contrast to the fifth proposition. The fifth proposition advocates for teachers to work with others to improve schools. If TFA believes current teachers in a schools are bad, they leave little opportunity to encourage their participants to collaborate and unite with each other to create a sense of shared-ownership of the problems in the school, a key concept which is espoused in feminist practices and the NBPTS (Helgesen, 1990; NBPTS, 2016). An alternative approach to a program like TFA could be one in which new teachers are partnered with experienced mentor teachers in their first years of teaching to learn, grow and collaborate with each other, rather than using a false narrative that places teachers in opposition.

\section{Tracking}

Students often are subjected to some sort of tracking by the beginning of Kindergarten and continue to experience this through high school. For example, they may be placed in the bluebird reading group while others are placed in the robins or encouraged to take AP classes in high school while others are pushed into vocational education. This system often separates students into homogeneous racial and socioeconomic groups from the beginning (Berliner \& Glass 2014). It groups already disadvantaged students together and offers them fewer resources than their peers to get on to a higher track (Gamoran, 1992; Oakes, 1985). Tracking students is patriarchal in principle because it offers 
specific institutional opportunities, like access to educational programs, to groups who already enjoy socioeconomic privileges (Messner, 1997).

Tracking students is in direct conflict with the NBPTS and feminist pedagogical practices because it does not allow for collaboration among students or opportunities in the classroom to collaborate with a diverse group of students. This limits students' ability to construct collective knowledge from those with different points of view (Gore, 1993; Lee, Mingyeh, \& Johnson-Bailey, 2004; Mogadime, 2003; Welch, 2006). Tracking automatically separates students from different backgrounds before they are even given the opportunity to learn together. The second proposition calls on teachers to create multiple pathways to knowledge so that students from all backgrounds and skills sets can access content (NBPTS, 2016). In doing so, they embrace their students' diverse backgrounds and do not rely on one standardized teaching practice to reach students (Griffiths, 2006).

\section{English-Only - English Learner Programs that Claim Superiority to Bilingual Programs}

English-only mandates for newly arrived English learners are prevalent all over the country. Two of the most well known states with this policy are Arizona, and until recently, California. These programs are formed with the assumption that English language learners learn English faster and better if they are given a "sink or swim" model which totally immerses them into all academic classes where English is the only language spoken (Berliner \& Glass, 2014). These programs are often designed for students to abandon their culture and language for the 
dominant English speaking culture, subtracting student's identities from the learning process (Valenzuela, 1999). English-only immersion programs are patriarchal by design because they favor white middle class students who already enjoy significant sociopolitical advantages (Messner, 1997).

Studies found that students in these programs often experience a wider gap in achievement than those who participate in bilingual programs (Rumberger \& Tran, 2010). English-only immersion programs lack feminist components that support diversity found in the NBPTS. The first proposition states that teachers must recognize individual differences in their students and acknowledge the different language practices of their students. They bring English learners into the learning process and respect the unique knowledge and perspectives they hold (NBPTS, 2016). While teachers in English-only programs may do this on their own in the classroom, they are working against the tide of a policy that does not encourage teachers to acknowledge and embrace their students' diversity and individual identity, making it challenging to find curriculum and professional development that help them make these connections with students. (Kishimoto \& Mwangi, 2009; Weiler, 1988).

\section{Aligning Standards, Policy, and Practice}

The NBPTS are considered the national standard for teaching excellence. This is evident because most states provide monetary awards for those teachers who complete the certification. As this study demonstrates, when accomplished teachers meet these standards, they are committed to both 
feminist philosophies and practices whether they think in feminist terms or not. This is largely problematic, not because it discourages men from pursuing teaching careers, but because there is an abundance of teaching policies in America today that directly contradict professional standards. As a result, teachers are faced with contradictory expectation, causing them to be forced to make decisions that either contradicts the expectation for exceptional teaching practice, or break the law. Not only is this asinine for teachers, it hurts our students ability to access the kind of education we expect teachers to deliver.

If society wants to see real improvement in our education system, it behooves policy makers to engage with the standards, gain a comprehensive understanding of what is the profession expects of teachers in the classroom on a daily basis, and then write policy based on those expectations. Until education reaches a point where teachers are given a clear set of expectation that are consistent with policy they will continue to remain dissatisfied with classroom teachers' philosophies and practices.

\section{Areas of Further Study}

This study examined the occurrence of feminist pedagogical practices throughout the NBPTS. It revealed that the standards are in fact aligned with feminist teaching practices and uncovered many education policies that contradict teaching practices and philosophies espoused by the standards. Further research on this topic is necessary for uncovering contradictory 
mandates within the profession that lead to unsound or undesirable classroom teaching.

The NBPTS could be cross-examined with major education policy to document where policy aligns and where it diverges with the national standards. This would require researchers to define the policy language and "What Teachers Should Know and Be Able to Do" and examine the discourse in each document. Through this examination we could learn which parts of the policy supports the teaching standards and what aspects of the policy contradicts the NBPTS. This would help educators and stakeholders to advocate for better-aligned policies. It does also provide policy makers with a roadmap on how to improve legislation.

Another study that may be worth exploring is a field study of Nationally Board Certified teachers. Data regarding their instances of feminist classroom practices vs. patriarchal classroom practices could provide a deeper understanding of NBPTS practices that are implemented in the classroom. A study such as this would move away from the documents and text and deeply examine the actual practices of teachers who receive National Board Certification. This research could research could shed more light on which practices teachers find most effective in the classroom setting.

There are also many opportunities for further research involving occurrences of feminist pedagogical practices in other documents that outline educator's expectations. The NBPTS are not the only document that outlines expectation for educators. Teaching organizations, governments, universities, and interests 
groups have published their versions of standards, expectations, and guidelines for educators. These documents hold different weights and serve different purposes. However, an examination like this would open up dialogues among these interests groups that could lead to clearer more concise communication of expectations with our teachers.

This research can also support further political organizing within the teaching profession. There is a clear gap between policy makers' understanding of the profession and actual exemplary teaching practices. To create meaningful change in this area teachers must engage with policy makers and the community. Accomplishing a task like this takes massive organizing efforts within the profession. Teachers' unions and professional associations have worked for decades on trying to bridge this gap. However, teachers will need to consistently put forth stronger more public efforts to accomplish this goal and change the course of current education policy.

\section{Conclusion}

This research examines the NBPTS booklet "What Teachers Should Know and be Able to Do" through feminist discourse analysis. Five Core Propositions (FCP) are outlined in the booklet and are typically referred to in the field as the "National Board Teaching Standards." This research identified how and where feminist pedagogy intersected with the FCP. While authors' original intent may not have been to intentionally incorporate feminist pedagogy into the text, it is clearly present throughout the document. 
This project chose three core feminist values to examine in the document: care, diversity, and collaboration. Caring is defined as having a fondness for the world and the people in it and developing a commitment to morally act on the behalf of others (Regan \& Brooks, 1995). Diversity is defined as the differences based on social categories like gender, race, sexuality, class, and others (Adams, 2013). An appreciation for diversity is revealed in non-standardized forms of teaching practices and the implementation of teaching practices that illustrate the benefits of human difference (Griffith, 2006). Finally, collaboration, being the ability to work with a group, offering support to each other, and creating a synergistic environment for everyone (Regan, \& Brooks, 1995). It's important to refocus the way the nation discusses teaching. We must move away from gender and instead emphasize teachers' pedagogical practices. 


\section{References}

Adams, M. (2013). Conceptual frameworks. M. Adams, W. J. Blumenfeld, C. Castañeda, H. W. Hackman, \& M. L. Peters, (Eds.), Readings for diversity and social justice. (pp.1-5). New York, NY: Taylor \& Francis.

Apple, M. W. (2001). Educating the "right" way: markets, standards, God, and inequality. New York, NY: Taylor \& Francis.

Asher, S. R., \& Gottman, J. M. (1973). Sex of teacher and student reading achievement. Journal of Educational Psychology, 65(2), 168.

Bank, B. J., Biddle, B. J., \& Good, T. L. (1980). Sex roles, classroom instruction, and reading achievement. Journal of Educational Psychology, 72 (2), 119.

Barnes, P. (Producer), \& Burns, K. (Director). (2003). Not for ourselves alone: The story of Elizabeth Cady Stanton \& Susan B. Anthony [Motion picture]. United States of America: PBS.

Beauvoir, S. D. (2011). The second sex. New York, NY: Random House, Inc.

Butler, J. (1986). Sex and gender in Simone de Beauvoir's second sex. Yale French Studies, 72, 35-49.

Belenky, M. F., Clinchy, B. M., Goldberger, N. R. \& Tarule, J. M. (1986). Women's ways of knowing: The development of self, voice, mind. New York, NY: BasicBooks.

Berliner, D.C., \& Glass, G. V. (Eds.). (2014). 50 myths and lies that threaten America's public schools: The real crisis in education. New York, NY: Teachers College Press.

Biddulph, S. (1998). Manhood: An action plan for changing men's lives. Stroud, UK: Hawthorn Press Ltd.

Brophy, J. E., \& Laosa, L. M. (1971). Effect of a male teacher on the sex typing of kindergarten children. Proceedings of the Annual Convention of the American Psychological Association, 6 (Pt. 1), 169-170.

Buerkle, C. W. (2004). The discipline and disciplining of Margaret Sanger: US Birth control rhetoric in the early twentieth century (Doctoral dissertation, Lousiana State University). Retrieved from https://digitalcommons.lsu.edu/gradschool_dissertations/1297/ 
Boal, A. (2001). Theater of the Oppressed. New York, NY: Theatre Communications Group, Inc.

Butler, J. (1990). Gender trouble: Feminism and the subversion of identity. New York, NY: Routledge.

Butler, J. (1988). Performative acts and gender constitution: An essay in phenomenology and feminist theory. Theatre journal, 40 (4), 519-531.

Campbell, K. K. (1989). Man cannot speak for her. Santa Barbara, CA: Praeger.

Cannard, K. (2017). National board certification: A career imprint that transfers to teacher leadership roles (Doctoral dissertation, Harvard Graduate School of Education). Retrieved from https://dash.harvard.edu/handle/1/33052845

Carrington, B., Francis, B., Hutchings, M., Skelton, C., Read, B., \& Hall, I. (2007). Does the gender of the teacher really matter? Seven-to eight-year-olds' accounts of their interactions with their teachers. Educational Studies, 33 (4), 397-413.

Chang, M. J. (2002). The impact of an undergraduate diversity course requirement on students' racial views and attitudes. The Journal of General Education, 51 (1), 21-42.

Cirksena, K., \& Cuklanz, L. (1992). A guided tour of five feminist frameworks for communication studies. In L. Rakow (Ed.), Women making meaning: New feminist directions in communication (pp. 18-44). New York, NY: Routledge.

Clifford, G. J. (1989). Man/woman/teacher: Gender, family, and career in American educational history. In D. Warren (Ed.), American teachers: Histories of a profession at work (pp. 293-343). New York, NY: Macmillan.

Darling-Hammond, L. (1999). Reshaping teaching policy, preparation, and practice: Influences of the national board for professional teaching standards. New York, NY: AACTE Publications

Discipline fears as female teachers outnumber male peers by 12 to 1 . (2006, November 10). Evening Standard. Retrieved September 17, 2017, from https://www.standard.co.uk/news/discipline-fears-as-female-teachersoutnumber-male-peers-by-12-to-1-7085220.html

Drudy, S. (2008). Gender balance/gender bias: The teaching profession and the 
impact of feminisation. Gender and Education, 20(4), 309-323.

Drudy, S., Martin, M., O'Flynn, J., \& Woods, M. (2005). Men and the classroom: Gender imbalances in teaching. New York, NY: Routledge.

Elshtain, J. B. (1981). Public man, private woman. Princeton, NJ: Princeton University Press.

Peterson, J., \& Lewis, M. (2001). The elgar companion to feminist economics. Retrieved from https://www.e-elgar.com/shop/the-elgar-companion-tofeminist-economics? website=uk_warehouse

Freidel, F., \& Sidey, H. (2006). The Presidents of the United States of America. White House Historical Association.

Friedan, B. (1963). The feminine mystique. New York, NY: W. W. Norton \& Company, Inc.

Freire, P. (2000). Pedagogy of the oppressed. New York: Bloomsbury Publishing.

Fiss, O. M. (1994). What is feminism?. Ariz. St. Law Journal, 26, 413.

Gamoran, A. (1992). Synthesis of research: Is ability grouping equitable?. Educational Leadership, 50, 11-11.

Gardner, S., Dean, C., \& McKaig, D. (1989). Responding to differences in the classroom: The politics of knowledge, class, and sexuality. Sociology of Education, 62 (1), 64-74.

Gavey, N. (1989). Feminist poststructuralism and discourse analysis: Contributions to feminist psychology. Psychology of women quarterly, 13 (4), 459-475.

Gitomer, H. (2014). The impact of the national board for professional teaching standards: A review of the research. ETS Report Series. Retrieved from https://onlinelibrary.wiley.com/doi/abs/10.1002/j.2333-8504.2007.tb02075.x

Griffiths, M. (2006). The feminization of teaching and the practice of teaching: Threat or opportunity?. Educational Theory, 56 (4), 387-405.

Gross, A. (1976). The relationship between sex differences and reading ability: A study of children's performance in an Israeli kibbutz system. Paper presented at the sixth World Congress on Reading of International Reading Association, Singapore, August 1976 
Goldberg, M. (2018, March). Will Betsy DeVos Expand the School-to-Prison Pipeline?. New York Times, Retrieved from https://www.nytimes.com/2018/03/12/opinion/devos-school-prisonpipeline.html

Goldman, E. (2017). Anarchism and other essays. United States of America: Astonishing Stories.

Gore, J. M. (1993). The struggle for pedagogies: Critical and feminist discourses as regimes of truth. New York: Routledge.

Helgesen, S. (1990, May). The pyramid and the web. New York Times, pp. F13.

Hewitt, N. A. (2012). Feminist frequencies: Regenerating the wave metaphor. Feminist Studies, 38 (3), 658-680.

Hobgood, M. E. (2012). Feminist classrooms as counterpublic spaces: Notes on the education they provide and the challenges they face. Journal of Feminist Studies in Religion, 28(1), 189-195.

Hoff Sommers, C. (2000). The war against boys: How misguided feminism is harming our young men. New York, NY: Touchstone.

Hooks, B. (2010). Teaching critical thinking: Practical wisdom. New York, NY: Routledge.

Hooks, B. (2015). Feminism is for everybody: Passionate politics. New York, NY: Routledge.

Hooks, B. (1994). Teaching to transgress: Education as the practice of freedom New York, NY: Routledge.

Francis, R.W. (n.d.). The equal rights amendment: Unfinished business for the constitution. Retrieved July 01, 2017, from http://www.equalrightsamendment.org/states.htm

Irvine Belson, S., \& Husted, T. A. (2015). Impact of national board for the professional teaching standards certification on student achievement. Education Policy Analysis Archives/Archivos Analíticos de Políticas Educativas, (23).

Jaggar, A. M. (1983). Feminist politics and human nature. Lanham, MD: Rowman \& Littlefield. 
Johnson, J. R., \& Bhatt, A. J. (2003). Gendered and racialized identities and alliances in the classroom: Formations in/of resistive space. Communication Education, 52(3-4), 230-244.

Kazemek, F. E. (1989). Feminine voice and power in moral education. Educational Horizons, 67(3), 76-81.

Kishimoto, K., \& Mwangi, M. (2009). Critiquing the rhetoric of "safety" in feminist pedagogy: Women of color offering an account of ourselves. Feminist Teacher, 19(2), 87-102.

Kohn, A. (2000). The case against standardized testing: Raising the scores, ruining the schools. Portsmouth, NH: Heinemann.

Lahaderne, H. M., \& Cohen, S. (1972, April). Freedom and fairness: A comparison of male and female teachers in elementary classrooms. In annual meeting of the American Educational Research Association, Chicago.

Lee, Ming-yeh, and Juanita Johnson-Bailey. (2004). Challenges to the classroom authority of women of color. New Directions for Adult \& Continuing Education 102 (2004) 55-64.

U.S. Department of Education, Office of Civil Rights (2014). Joint "Dear Colleague" Letter on the Nondiscriminatory administration of school discipline. (pp. 1-23) Retrieved on July 8, 2017 from https://www2.ed.gov/about/offices/list/ocr/letters/colleague-residentialfacilities-201412.pdf

Lingard, B. (2003). Where to in gender policy in education after recuperative masculinity politics?. International Journal of Inclusive Education, 7(1), 33-56.

Lorde, A. (1980). Sister Outsider. New York, NY: Random House.

Martino, W., \& Berrill, D. (2003). Boys, schooling and masculinities: Interrogating the 'right' way to educate boys. Education Review, 55(2), 99-117.

Martino, W., \& Kehler, M. (2006). Male teachers and the" boy problem": An issue of recuperative masculinity politics. McGill Journal of Education, 41(2), 113.

McCall, L. (2005). The complexity of intersectionality. Signs: Journal of women in culture and society, 30(3), 1771-1800.

McGee, M. C. (1980). The "ideograph": A link between rhetoric and ideology. 
Quarterly journal of speech, 66(1), 1-16.

Messner, M. A. (1997). Politics of masculinities: Men in movements. Lanham, MD: Altamira Press.

Merchant, C. (1995). Ecology: Key concepts in critical theory. Amherst, NY: Humanity Books.

Mills, M. (2004). Male teachers, homophobia, misogyny and teacher education. Teaching Education, 15(1), 27-39.

Mills, M., \& Lingard, B. (1997). Masculinity politics, myths and boys' schooling: A review essay. British Journal of Educational Studies, 45(3), 276-292.

Mills, M., Martino, W., \& Lingard, B. (2004). Attracting, recruiting and retaining male teachers: Policy issues in the male teacher debate. British Journal of Sociology of Education, 25(3), 355-369.

Mosher, D. L., \& Tomkins, S. S. (1988). Scripting the macho man: Hypermasculine socialization and enculturation. Journal of Sex Research, 25(1), 60-84.

Mogadime, D. (2003). Contradictions in feminist pedagogy: Black women students' perspectives. Resources for Feminist Research, 30(12), 7-32.

Montgomery, S. E. (2009). Why men left. American Educational History Journal, 36(1-2), 219-236.

Musial, J. (2011). Engaged pedagogy in the feminist classroom and yoga studio. Feminist Teacher, 21(3), 212-228.

National Board for Professional Teaching Standards. (2016). What Teachers Should Know and be Able to Do. Retrieved July 17, 2017 from http://accomplishedteacher.org/wp-content/uploads/2016/12/NBPTS-WhatTeachers-Should-Know-and-Be-Able-to-Do-.pdf

NEA Code of Ethics Code of Ethics. (n.d.). Retrieved February 03, 2018, from http://www.nea.org/home/30442.htm

New No Child Left Behind Flexibility: Highly Qualified Teachers. (2005, December 19). Retrieved February 03, 2018, from https://www2.ed.gov/nclb/methods/teachers/hqtflexibility.html 
Newsom, J. S. (Producer, Director). (2015). The mask you live in. [Motion Picture]. United States: The Representation Project.

Nichols, S. L., \& Berliner, D. C. (2007). Collateral damage: How high-stakes testing corrupts America's schools. Cambridge, MA: Harvard Education Press.

Noddings, N. (1984). Caring: A feminine approach to ethics. Berkeley, CA: University of California Press.

Noddings, N. (1992). The challenge to care in schools: An alternative approach to education. New York, NY: Teacher College Press.

Noddings, N. (2008). Caring and peace education. In M. Bajaj (Ed.) Encyclopedia of peace education (87-91). Charlotte, NC: Information Age Publishing.

Oakes, J. (1985). Keeping track: How schools structure inequality. New Haven, CT: Yale University Press.

O'Day, J. A., \& Smith, M. S. (1993). Systemic reform and educational opportunity. Designing coherent education policy: Improving the system, 250312.

Okin, S. M. (1979). Rousseau's Natural Woman. The Journal of Politics, 41(2), 393-416.

Panko-Stilmock, J. L. (1996). Teacher gender and discipline referral rates for middle level boys and girls. University of Nebraska-Lincoln. Retrieved from https://digitalcommons.unl.edu/dissertations/AAI9715979

Partington, G. (1977). Women teachers in the 20th century in England and Wales. London, England: Nelson Publishing Company.

Potter, J., \& Wetherell, M. (1987). Discourse and social psychology: Beyond attitudes and behaviour. New York, NY: Sage Publications.

Regan, H. B., \& Brooks, G. H. (1995). Out of women's experience: Creating relational leadership. Thousand Oaks, CA: Corwin Press, Inc.

Reuman, A. E., \& Anzaldúa, G. E. (2000). Coming into play: an interview with Gloria Anzaldua. Melus, 25(2), 3-45.

Richards, J. C., \& Schmidt, R. W. (2013). Longman dictionary of language teaching and applied linguistics. New York, NY: Routledge. 
Rich, M. (2014, September 06). Why Don't More Men Go Into Teaching?. New York Times. Retrieved July 25, 2017, from https://www.nytimes.com/2014/09/07/sunday-review/why-dont-more-men-gointo-teaching.html

Richardson, S. (2012). Elementary school:(Hyper) masculinity in a feminized context. Rotterdam, The Netherlands: Sense Publishers.

Rosser, S. V. (2000). Women, science, and society: The crucial union. New York, NY: Teachers College Press.

Rothman, B. K. (1994). Beyond mothers and fathers: Ideology in a patriarchal society. E. N. Glen, G. Chang, \& Forcey, L. R. (Eds.) Mothering: Ideology, experience, and agency (139-157). New York, NY: Routledge.

Rumberger, R. W., \& Tran, L. (2010). State language policies, school language practices, and the English learner achievement gap. M. Hopkins (Ed.), Forbidden language: English learners and restrictive language policies (195215). New York, NY: Teachers College Press.

Sabbe, E., \& Aelterman, A. (2007). Gender in teaching: A literature review. Teachers and Teaching: theory and practice, 13(5), 521-538.

Sanchez, C. (2018, February 22). What decades of covering school shootings has taught me. NPR. Retrieved March 22, 2018, from https://www.npr.org/sections/ed/2018/02/22/587334597/what-decades-ofcovering-school-shootings-has-taught-me

Scott, J. W. (1986). Gender: A useful category of historical analysis. The American historical review, 91(5), 1053-1075.

Skelton, C. (2003). Male primary teachers and perceptions of masculinity. Educational review, 55(2), 195-209.

Smith, T. (2012, September 13). Teacher evaluation dispute echoes beyond Chicago. NPR. Retrieved March 22, 2018, from https://www.npr.org/2012/09/13/160247078/teacher-evaluation-disputeechoes-beyond-chicago

Spencer, L. G. (2015). Engaging undergraduates in feminist classrooms: An exploration of professors' practices. Equity \& Excellence in Education, 48(2), 195-211. 
Stahl, L. (Writer). (2018). Betsy DeVos on guns, school choice and why people don't like her. S. Bar-on (Producer). CBS 60 Minutes. Retrieved from https://www.cbsnews.com/news/secretary-of-education-betsy-devos-on-gunsschool-choice-and-why-people-dont-like-her/

Sykes, G. (1996). Reform-of and as-professional development. Phi Delta Kappan, 77(7), 464.

Thurber, F. (2005). Partnering for leadership in arts education. B. Rushlow (Ed.) The Evolving Roles of Supervisors and Administrators as Leaders of Change: Perspectives for a New Millennium (79-103). Reston, VA: National Art Education Association.

Thurber, F., \& Zimmerman, E. (2002). An evolving feminist leadership model for art education. Studies in Art Education, 44(1), 5-27.

Truth, S. (2004). Ain't I a Woman? C. Brezina (Ed.) Sojourner Truth's "ain't I a woman?" speech: A primary source investigation. New York, NY: Rosenpub Group.

Van Dijk, T. A. (Ed.) (1985). Handbook of discourse analysis (Vol. 3). New York, NY: Academic Press.

Vandevoort, L. G., \& Berliner, D. C. (2004). National Board Certified Teachers and Their Students' Achievement. Education policy analysis archives, 12(46), n46.

Valenzuela, A. (1999). Subtractive schooling: Issues of caring in education of US-Mexican youth. New York, NY: State University of New York Press.

Walby, S. (1990). Theorizing patriarchy (Vol. 20). Cambridge, MA: Blackwell Publishing.

Watson, G. C. (2008). Against from within: Finding feminist pedagogical spaces between academic institutional margins. Feminist Teacher, 9(1), 7 I.

Weiler, K. (1988). Women teaching for change: Gender, class \& power. Westport, CT: Bergin \& Garvey.

Welch, Penny. (2006). Feminist Pedagogy Revisited. Learning \& Teaching in the Social Sciences 3(3), 171-99. 
Wood, J. T. (2002). A critical response to John Gray's Mars and Venus portrayals of men and women. Southern Communications Journal, 67(2), 201-210.

Yuval-Davis, N. (2006). Intersectionality and feminist politics. European Journal of Women's Studies, 13(3), 193-209.

Zimmerman, A. L., McDermott, M. J., \& Gould, C. M. (2009). The local is global: Third wave feminism, peace, and social justice. Contemporary Justice Review, 12(1), 77-90. 